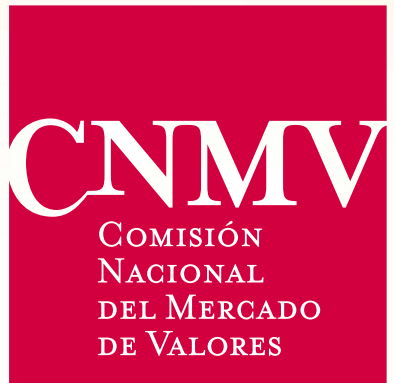

Rethinking Capital Regulation: The Case for a Dividend Prudential Target

Manuel Muñoz

Documentos de Trabajo $N^{\circ} 68$ 



\section{Rethinking Capital Regulation: The Case for a Dividend Prudential Target*}

Manuel Muñoz †

\section{Working paper}

No. 68

December 2018

\footnotetext{
* The views expressed in this paper are those of the author and do not necessarily reflect the views of the institutions he is affiliated to. I am indebted to Javier Andrés and Luis A. Puch for invaluable support and guidance. I also thank, without implicating, Jorge Abad, Pablo Aguilar, María José Fernández, Jordi Galí, Samuel Hurtado, Laura Mayoral, Galo Nuño, Johannes Pfeifer, Dominik Thaler and Carlos Thomas for very helpful comments and suggestions, as well as participants in seminars at the Spanish Securities Exchange Commission (CNMV) and at Universidad Complutense de Madrid. I am responsible for all remaining errors. tSpanish Ministry for Economy and Business.
} 
The views expressed in this paper are those of the author and do not necessarily represent the views of the Spanish Ministry for Economy and Business, its Managers, or the CNMV.

The CNMV publishes this Working Paper Series to enhance research and contribute towards greater knowledge of the stock markets and their regulation.

The CNMV distributes its reports and publications via the internet at www.cnmv.es

(C) CNMV. The contents of this publication may be reproduced, subject to attribution.

Layout \& printing: Composiciones Rali, S.A. 


\section{Abstract}

The paper investigates the effectiveness of dividend-based macroprudential rules in complementing capital requirements to promote bank soundness and sustained lending over the cycle. First, some evidence on bank dividends and earnings in the euro area is presented. When shocks hit their profits, banks adjust retained earnings to smooth dividends. This generates bank equity and credit supply volatility. Then, a DSGE model with key financial frictions and a banking sector is developed to assess the virtues of what shall be called dividend prudential targets. Welfare-maximizing dividend-based macroprudential rules are shown to have important properties: (i) they are effective in smoothing the financial cycle by means of less volatile bank retained earnings, (ii) they induce welfare gains associated to a Basel III-type of capital regulation, (iii) they mainly operate through their cyclical component, ensuring that long-run dividend payouts remain unaffected, (iv) they are flexible enough so as to allow bank managers to optimally deviate from the target, and (v) they act as an insurance scheme for the real economy.

Keywords: macroprudential regulation, capital requirements, dividend prudential target, financial stability, bank dividends

JEL classification: E44, E61, G21, G28, G35 



\section{List of Contents}

3 The Basic Model

3.1 Main Features

3.2 Quantitative Exercise

4.1 Overview of the model

5 Quantitative Analysis $\quad 37$

\begin{tabular}{llr}
\hline 5.1 & Calibration & 37
\end{tabular}

\begin{tabular}{llr}
\hline 5.2 Welfare Analysis & 39
\end{tabular}

\begin{tabular}{llr}
\hline 5.3 & Robustness Checks & 44
\end{tabular}





\section{List of Tables}

\begin{tabular}{llr} 
TABLE 1 & Optimized rules and prudential losses; collateral shock (basic model) & 51 \\
\hline TABLE 2 & Baseline parameter values & 52 \\
\hline TABLE 3 & Steady state ratios & 53 \\
\hline TABLE 4 & Welfare gains & 54 \\
\hline TABLE 5 & Welfare gains and capital regulation & 55 \\
\hline TABLE 6 & Welfare gains and the CCyB & 56 \\
\hline TABLE 7 & Robustness checks & 56 \\
\hline
\end{tabular}

\section{List of Figures}

\begin{tabular}{llr} 
FIGURE 1 & Bank dividends and earnings in the euro area. 2002:I - 2018:Il & 57 \\
\hline FIGURE 2 & Impulse-responses to a negative collateral shock (basic model, baseline scenario) & 58 \\
\hline FIGURE 3 & $\begin{array}{l}\text { Impulse-responses to a negative collateral shock (basic model, optimized } \\
\text { prudential rules) }\end{array}$ & 58 \\
\hline FIGURE 4 & Welfare effects of ceteris paribus changes in $\rho_{\mathrm{d}}$ and $\rho_{\mathrm{x}}$ & 59 \\
\hline FIGURE 5 & Welfare effects of ceteris paribus changes in $\rho_{\mathrm{x}}$ (shutting down shocks one by one) & 59 \\
\hline FIGURE 6 & Welfare effects of ceteris paribus changes in $\gamma_{\mathrm{x}}$ and $\rho_{\mathrm{x}}+\gamma_{\mathrm{x}}$ & 60 \\
\hline FIGURE 7 & Impulse-responses to a negative collateral shock (extended model, \\
\hline macroprudential policy scenarios)
\end{tabular}





\section{Introduction}

The recent financial crisis has highlighted the importance of counting with a comprehensive prudential regulatory framework that includes macroprudential tools to smooth the financial cycle and prevent the endogenous build-up of systemic risk (see, e.g., Galati and Moessner 2013, Constâncio 2017). Regulatory capital ratios remain a central element of such toolkit. Some of the key objectives financial regulators pursue with this policy instrument are to ensure soundness of banks and normal lending activities during economic downturns. However, the attainment of such objectives cannot be taken for granted since macroeconomic effects of meeting capital requirements heavily depend on the channel through which banks adjust their capital ratios. ${ }^{1}$

In order to increase its regulatory capital ratio, a bank can either raise capital (numerator) or decrease total risk-weighted assets (denominator). The denominator can be reduced either by shrinking total assets - in many cases via cutting back on lending - or by reducing their assets' risk weighted average (substitution of riskier assets for safer ones). The main caveat of the latter is that a risk shift of this kind may not necessarily contribute to sustained lending. For instance, the replacement of "risky" loans for public debt is an alternative way of restricting credit supply to the private sector.

Perhaps, one of the most powerful mechanisms to meet capital requirements while enhancing bank solvency and lending to the real economy is to directly raise capital. There are two main options in this regard: to issue new equity or to retain earnings. The issuance of new equity can be effective but it has a number of disadvantages that make it one of the least attractive strategies to raise capital on a regular basis: (i) it is costly, (ii) the desire of attracting new shareholders often pushes banks to increase their dividend payout ratios (retained earnings decreases), and (iii) it is the least attractive option for existing bank shareholders as a new share issue tends to reduce the market value of the existing shares.

Alternatively, the bank can opt to retain more earnings. Retained earnings represent the core component of high quality regulatory capital and a source of regular capital accumulation at a low direct cost. The bank can target higher retained earnings either by boosting total profits or by reducing its dividend payout ratio. The direct way of increasing profits is by enlarging the lending spread. Yet, competition in lending markets can even deter big banks from choosing this option. Beyond the fact that non bank lending has constantly gained weight since the outbreak of the recent crisis, small banks themselves can improve their market share (against big banks) by compressing their margins.

\footnotetext{
${ }^{1}$ According to the evidence, bankers internally set their own target capital ratio. This ratio usually includes a buffer above the regulatory capital requirement. To the extent that such buffer is directly related to the capital requirement, I indistinctly use expressions "meeting capital requirements " and "adjusting capital ratios" to make reference to the action by which bankers adjust their regulatory capital ratio towards their internal target.
} 
Regarding the alternative of cutting back dividends, the challenge is that markets (shareholders) immediately react to dividend announcements and penalize lower-than-expected dividend payments. Nevertheless, in this case there is a strong, economic theory-based reason that may justify public intervention. According to the evidence, large, established corporations (including banks) distribute a significant percentage of their profits in the form of dividends and they tend to smooth them over the cycle. There is a vast literature arguing there are certain market imperfections behind this pattern. Among others, asymmetric information (agency problems) and incomplete contracts. See Lintner (1956), Miller and Rock (1985), Dewenter and Warther (1998), La Porta et al. (2000), Allen and Michaely (2003), and DeAngelo et al. (2009), among others.

The joint consideration of several recent empirical studies points to the existence of a link between the dividend policies of euro area banks and the adjustment mechanisms through which they improved their capital ratios in the aftermath of the Great Recession. Based on the statement that retained earnings is the most important source of banks' own funds, Shin (2016) documents on the accumulated dividends and retained earnings during 2007-2014 for a sample of 90 euro area banks, to conclude that for certain eurozone countries, "retained earnings would have been more than double what it was at the end of 2014, had profits been ploughed back into the bank."

In addition, Cohen and Scatigna (2016) show that for the period 2009-2013 the euro area banking sector was boosting regulatory capital ratios, foremost via asset shrinking, while virtually the rest of the world was doing so, primarily by means of capital increases. This evidence is aligned with the main findings in Gropp et al. (2018). Taking the EBA 2011 capital exercise as a quasi natural experiment, these authors show that European banks which had to raise their core tier 1 capital ratios in response to the mentioned exercise did it by reducing their levels of risk-weighted assets rather than by increasing their levels of capital. More precisely, they engaged in asset shrinking rather than in risk reduction. A reduction in total assets that has been mainly attributed to a reduction in outstanding customer loans, with effects on the real economy.

The objective of this paper is to evaluate the effectiveness of dividend-based prudential regulation for banks in complementing the existing capital regulation in its aim of improving bank soundness, financial stability, and social welfare. ${ }^{2}$

The proposal for regulating bank dividends as a complement of capital requirements is not a new one. As argued in Acharya et al. (2012), "The erosion of common equity was exacerbated by large scale payments of dividends, in spite of widely anticipated credit losses. Dividend payments represent a transfer from creditors (and potentially taxpayers) to equity holders in violation of the priority of debt over equity..Thus, an early imposition of regulatory sanctions against the paying of dividends (for instance, as part of an increasing "ladder of sanctions" that are based on market

\footnotetext{
${ }^{2}$ Basel III regulation states that credit institutions face no restrictions on their dividend policies provided that they comply with the minimum capital requirement plus the conservation buffer ( $10.5 \%$ of risk-weigthed assets). The regulation says little about the adjustment mechanisms through which banks should meet their capital requirements.
} 
or common-equity based notions of bank leverage) may have an important place in the agenda for reform of the regulatory system ${ }^{\prime \prime}{ }^{3}$ Moreover, Goodhart et al. (2010) follow a two-period modeling approach to assess the impact of imposing dividend restrictions on the functioning of the interbank market. Acharya et al. (2017) provide theoretical rationale for the use of dividend restrictions for banks. Similarly, Admati et al. (2013) advocate dividend restrictions and capital conservation in bad times.

To the best of my knowledge, there hasn't been any work in which a DSGE modeling approach is adopted to asses the relevance of bank dividend regulation as a macroprudential tool in a world of capital requirements.

On these grounds, and based on the available evidence, this paper develops a financial business cycle model which incorporates the following key features: (i) bank capital accumulation out of retained earnings, (ii) endogenous bank dividend policies, and (iii) a set of financial frictions that makes bankers to optimally adjust capital ratios through the retained earnings and credit supply channel in order to smooth dividends. Such imperfections impede aggregate financial and economic fluctuations to be optimal from a social welfare point of view.

To account for equity payout smoothing, the model relies on a dividend payout adjustment cost function, in the spirit of Jermann and Quadrini (2012). The role this modeling device plays in the model is twofold: (i) it endogenously generates a pattern of bank dividend smoothing over the cycle, and (ii) it is instrumental in the specification and transmission of the proposed prudential rule.

In the same way Angelini, Neri and Panetta (2014) specify a target for dynamic capital requirements, the model incorporates a dynamic regulatory target for bank dividends. The main difference between their approach and the one followed in this paper is that, in this case, the extra cost bankers can incur when deviating from what shall be called the "dividend prudential target" is not taken as a deadweightloss. Rather, the paper assumes such cost takes the form of a penalty payment or sanction that is collected by the prudential authority and directly transferred as a net subsidy to the non financial sector of the economy.

The rest of the model builds on a number of recent contributions to the macro-finance literature which have been essential to shed light on the macroeconomic implications of financial interactions. The main role of the banking sector in this model is to allow for resource transfers between savers and borrowers. In the spirit of Bernanke et al. (1999), the presence of certain frictions enables financial intermediation activities to endogenously propagate and amplify shocks to the macroeconomy. As in Gertler and Karadi (2011) and Gertler and Kiyotaki (2010), bankers face a balance sheet constraint when obtaining deposits. In the tradition of Kiyotaki and Moore (1997),

\footnotetext{
${ }^{3}$ These authors carry out an empirical analysis based on U.S. banking data for the period 2007-2009 to draw some general conclusions and give specific recommendations on capital regulation.
} 
borrowers are constrained in their capacity to borrow by the value of their real estate collateral. Based on Iacoviello (2015), financial intermediaries face a similar type of borrowing constraint which can be interpreted as a capital adequacy restriction. ${ }^{4}$ That implies regulatory capital ratios are binding in a neighborhood of the steady state. This assumption is important in order to focus the attention on the effects of a possibility not considered in the Basel III Accord. To regulate bank dividend policies even when credit institutions comply with capital requirements. The general structure of the model has its similarities to Gerali et al. (2010).

In a first stage, a stylized version of the model is presented to clearly identify the transmission channel through which the proposed policy rule complements capital ratios in the attainment of their goals. A quantitative exercise is carried out to show that simple dividend prudential targets which react to deviations of the credit-to-output gap call for procyclical, relatively more volatile bank dividends in order to smooth the financial cycle.

Then, the model is extended as in Iacoviello (2005). Incorporating an additional type of borrower (impatient households) and physical capital helps to improve the dynamics of the model and its matching to quarterly euro area data. The welfare analysis results suggest that savers and borrowers benefit from countercyclical dividend prudential targets. An important conclusion that can be drawn from the exercise is that dividend-based macroprudential rules are a very effective complement of dynamic capital requirements in smoothing the financial cycle and improving social welfare.

The paper is organized as follows. Section 2 presents empirical evidence on bank dividends and earnings in the euro area. Section 3 describes the basic model and identifies the transmission mechanism through which a dividend prudential target improves bank soundness and financial stability. Section 4 presents the extended model to improve the matching of the model to the data. Section 5 develops a quantitative exercise to asses the welfare effects of the proposed policy and its interactions with regulatory capital ratios. Section 6 concludes.

\footnotetext{
${ }^{4}$ This capital adequacy constraint can be interpreted as the overall regulatory capital ratio bankers target internaly. According to the evidence, such target ratio typically includes a buffer bankers maintain above the minimum capital requirement imposed by the financial regulator. Some of the factors that determine such buffer are profitability, risk, size and loan loss provisions.
} 


\section{Patterns of Bank Dividends in the Euro Area}

Figure 1 describes some of the key patterns of euro area bank dividends and their link with equity developments. Plotted financial data is at quarterly frecuency and has been seasonally adjusted by means of the Tramo/Seats method. Financial data is from the Euro Stoxx Banks Index, SX7E. ${ }^{5}$ Given the purpose of the paper, such composite index has been selected as a representative group of the euro area banking system for several reasons. First, it captures relatively well the performance of the sector since it is composed of large, listed banks that are leaders in their industry in terms of market capitalization. Second, given the size and interconnectednes of its members, it is a fairly good sample of banks to carry out systemic risk analysis. Third, the signalling power of dividends is more evident for the case of large, listed companies. Fourth, the constructed series are from data that is available and updated by Bloomberg.

Figure 1(a) plots the euro area annual GDP growth rate (secondary y-axis) and the dividend payout ratio of the SX7E for the period 2002:I-20018:II. The dividend payout ratio is defined as the total net dividend payout (including all cash type of dividends and excluding returns of capital and in-specie dividends) as a percentage of net profits. The payout ratio is notably countercyclical and it becomes more volatile in times of severe financial stress (2009 and 2012). In 2009:II, distributed earnings represented about $82.5 \%$ of net profits while they exceeded $100 \%$ of total earnings in 2012II and 2012III.

Figure 1(b) sheds light on the main underlying drivers of such pattern. Especially from 2009:I onwards, bank managers opted to smooth dividends over the cycle, paying high and stable amounts of dividends in cash even if net income for the period was negative. Overall, both variables are procyclical, while earnings are relatively more volatile than dividends. ${ }^{6}$ Note that the spike of the dividend payout ratio in 2012:III relates to the July 2012 financial turmoil. Relying on the signalling role attributed to dividend policies, bankers maintained dividend payouts roughly stable despite the severe fall in earnings. ${ }^{7}$

Such a dividend policy has tangible implications for the composition and performance of bank

\footnotetext{
${ }^{5}$ The Euro Stoxx Banks Index, SX7E, is a capitalization-weighted index. The largest stocks in the EMU banking sector are selected to weigh in the index according to their free-float market capitalization. As of October 31,2018, the top ten components of the index (and their corresponding weights) were Banco Santander (16.42\%), BNP Paribas (12.90\%), ING Group (9.89\%), BBVA (7.90\%), Intesa Sanpaolo (7.73\%), Societe Generale Group (6.36\%), Unicredit (5.81\%), Deutsche Bank (4.01\%), KBC Group (3.87\%), and Credit Agricole (3.41\%).

${ }^{6}$ The sample allows to clearly identify two subperiods. A first one that goes until 2008:IV, in which both variables are highly procyclical and relatively volatile, and a second one - that ranges from 2009:I to 2018:II - in which aggegate dividends become less procyclical and relatively less volatile.

${ }^{7}$ The series presented in figure 1(b) may not necessarily coincide with the time series on the dividend payout ratio plotted in figure 1(a). Due to data availability, the former have been constructed as a simple sum of the SX7E members whereas the latter is a capitalization-weighted sum of the same group of banks. See Appendix A for more information on data construction.
} 
equity over the cycle and for the available adjustment mechanisms to meet the target capital ratio. Figure 1(c) plots equity and retained earnings of the SX7E for the same period. Not surprisingly, both aggregates are procyclical and highly correlated. Nonetheless, retained earnings are relatively more volatile, especially during economic downturns. That confirms two important findings. First, the adjustment in the face of shocks that affect banks' net profits is mainly borne by retained earnings (i.e., dividend smoothing). Second, retained earnings are an important driver of bank equity (and, hence, credit supply) falls during economic recessions.

All in all, these patterns suggest that bank managers assign a prominent signaling role to dividends. This becomes particularly clear in periods of financial stress. Consequently, retained earnings have to adjust severely (SX7E retained earnings reached a minimum in 2012:II). This evidence deserves especial attention from the policymaker. To the extent that issuing new equity in times of market stress and economic downturn is particularly costly, this art of dividend policies may be crucial to understand the preference of euro area banks for meeting capital requirements through asset shrinking. 


\section{The basic model}

Consider three types of agents who interact in a real, closed, decentralized and time-discrete economy in which all markets are competitive. Households work, consume, accumulate housing and invest their savings in one-period bank deposits. Entrepreneurs demand real estate capital and labor to produce an homogeneous final good. Due to a discrepancy in their discount factors, in the aggregate households are nets savers whereas entrepreneurs are net borrowers. There are financial flows in equilibrium. Bankers intermediate financial resources by borrowing from households and lending to entrepreneurs. They devote the resulting net profit to do both; pay dividends (bankers' consumption) and meet the capital requirement by retaining earnings. For each type of agent, there is a continuum of individuals in the $[0,1]$ interval.

In the spirit of Iacoviello (2005), entrepreneurs and bankers are assumed to face borrowing constraints that are binding in a neighborhood of the steady state. Consequently, the first best is unattainable in equilibrium. Moreover, the presence of credit and equity payout adjustment costs generates additional inefficiencies over the cycle. Such financial imperfections play two important roles: (i) they amplify the effects of exogenous shocks through the financial sector, and (ii) they open up the possibility of a welfare-improving public intervention.

The aim of this section is to identify the transmission mechanism through which the considered policy operates. In doing so, the paper evaluates its effectiveness in favouring financial stability by smoothing the credit cycle.

\subsection{Main Features}

\subsubsection{Households (net savers)}

Let $C_{h, t}, H_{h, t}$ and $N_{h, t}$ represent consumption, housing demand and hours worked by households in period $t$. The representative household seeks to maximize the objective function

$$
E_{0} \sum_{t=0}^{\infty} \beta_{h}^{t}\left[\log C_{h, t}+\log H_{h, t}-\frac{N_{h, t}^{1+\phi}}{(1+\phi)}\right]
$$

subject to the sequence of budget constraints

$$
C_{h, t}+D_{t}+q_{t}\left(H_{h, t}-H_{h, t-1}\right)=R_{h, t-1} D_{t-1}+W_{h, t} N_{h, t}
$$

where $D_{t}$ denotes the stock of deposits, $R_{h, t}$ is the gross interest rate on deposits, $q_{t}$ is the price of housing and $W_{h, t}$ the wage rate. Housing does not depreciate. $\beta_{h} \in(0,1)$ is the households' 
subjective discount factor, $j$ is the preference parameter for housing services and $\phi$ stands for the inverse of the Frisch elasticity. Each period, the representative household allocates its resources in terms of wage earnings, properties in the housing market and gross returns on total deposits between final consumption and investment in deposits and housing. The standard intertemporal and intratemporal optimality conditions can be derived from the first order conditions of the problem.

$$
\begin{gathered}
\frac{1}{C_{h, t}}=\beta_{h} R_{h, t} E_{t}\left(\frac{1}{C_{h, t+1}}\right) \\
\frac{q_{t}}{C_{h, t}}=\frac{j}{H_{h, t}}+\beta_{h} E_{t}\left(\frac{q_{t+1}}{C_{h, t+1}}\right) \\
\frac{W_{h, t}}{C_{h, t}}=N_{h, t}^{\phi}
\end{gathered}
$$

Expression (1) is the Euler equation for consumption, which in this model determines the equilibrium interest rate on deposits. Equation (2) refers to the optimality condition for intertemporal substitution between consumption and housing demand. Expression (3) is the labor supply schedule, relating real wages to the marginal rate of substitution between consumption and hours worked.

\subsubsection{Entrepreneurs (net borrowers)}

The representative entrepreneur chooses the trajectories of consumption $C_{e, t}$, housing $H_{e, t}$, demand for labor $N_{h, t}$ and bank loans $B_{t}$ that maximize

$$
E_{0} \sum_{t=0}^{\infty} \beta_{e}^{t} \log C_{e, t}
$$

subject to the sequence of budget constraints

$$
C_{e, t}+R_{e, t} B_{t-1}+q_{t}\left(H_{e, t}-H_{e, t-1}\right)+W_{h, t} N_{h, t}+\Phi_{e}\left(B_{t}\right)=Y_{t}+B_{t}
$$

where $B_{t}$ stands for bank loans, $R_{e, t}$ is the gross interest rate on loans, and $\Phi_{e}\left(B_{t}\right)=\frac{\phi_{e}}{2} \frac{\left(B_{t}-B_{t-1}\right)^{2}}{B^{s s}}$ is a quadratic loan portfolio adjustment cost, assumed to be external to the entrepreneur as in Iacoviello (2015). This cost discourages the entrepreneur from changing their credit balances too quickly, thereby contributing to match the empirical fact that bank credit varies slowly over time. $Y_{t}$ is final output. $B^{s s}$ is the steady-state value of $B_{t}$ and $\phi_{e}$ is the loans adjustment cost para- 
meter. $\beta_{e} \in(0,1)$ is the subjective discount factor of the entrepreneur, which is assumed to be strictly lower than $\beta_{h}$, implying that, in equilibrium, households are net savers and entrepreneurs are net borrowers. Each period, the representative entrepreneur devotes her resources in terms of produced final output and loans to consume, repay its debt, remunerate productive factors and adjust credit demand.

The homogeneous final good is produced by using a Cobb-Douglas technology that combines labor and commercial real estate as follows ${ }^{8}$ :

$$
Y_{t}=H_{e, t-1}^{v} N_{h, t}^{1-v}
$$

In addition, entrepreneurs are subject to

$$
B_{t} \leq m_{t}^{H} E_{t}\left(\frac{q_{t+1}}{\left(1+r_{e, t+1}\right)} H_{e, t}\right)-m^{N} W_{h, t} N_{h, t}
$$

Expression (4) dictates that the borrowing capacity of entrepreneurs is tied to the value of their collateral. In particular, they cannot borrow more than a possibly time-varying fraction $m_{t}^{H}$ of the expected value of their real estate stock. More precisely, $m_{t}^{H}=m^{H} \varepsilon_{t}^{m h}$ is the exogenously timevarying loan-to-value ratio, where $m^{H} \in[0,1]$ and $\varepsilon_{t}^{m h}$ follows a zero-mean $\operatorname{AR}(1)$ process with autorregressive coefficient equal to $\rho_{m h}$ and i.i.d innovations $e_{m h, t}$ that are normally distributed and have a standard deviation equal to $\sigma_{m h}$. Moreover, the borrowing constraint indicates that a fraction $m^{N} \in[0,1]$ of the wage bill must be paid in advance, as in Neymeyer and Perri (2005). ${ }^{9}$

As in Iacovielllo (2015), entrepreneurs are assumed to discount the future more heavily than households and bankers. Formally, $\beta_{e}=\frac{1}{\gamma \frac{1}{\beta_{h}}+(1-\gamma) \frac{1}{\beta_{b}}}$, an assumption that ensures the borrowing constraint is binding in a neighborhood of the steady state. ${ }^{10}$

The optimality conditions for housing and labor demand can be obtained from the first order conditions

\footnotetext{
${ }^{8}$ The specification of a production function in which real estate enters as an input has become common practice in the macro-finance literature. See, e.g., Iacoviello (2005 and 2015), Andrés and Arce (2012) and Andrés et al. (2013).

${ }^{9}$ Whitout loss of generality, this assumption is made for quantitative analysis-related reasons. It helps in shaping the steady state levels and transition dynamics of aggregate financial variables, particularly in a reduced form model of this kind.

${ }^{10} \mathrm{As}$ it will be shown later, $\beta_{b}$ is the discount factor of bankers and $\gamma \in[0,1]$ refers to their borrowing capacity expressed in terms of banks' total assets.
} 


$$
\begin{gathered}
\frac{1}{C_{e, t}}\left[q_{t}-\left(1-\frac{\partial \Phi_{e}\left(B_{t}\right)}{\partial B_{t}}\right) m_{t}^{H} E_{t}\left(\frac{q_{t+1}}{R_{e, t+1}}\right)\right]=\beta_{e} E_{t}\left\{\frac{1}{C_{e, t+1}}\left[q_{t+1}\left(1-m_{t}^{H}\right)+v\left(\frac{Y_{t+1}}{H_{e, t}}\right)\right]\right\} \\
\frac{1}{C_{e, t}}\left[W_{h, t}+m^{N} W_{h, t}\left(1-\frac{\partial \Phi_{e}\left(B_{t}\right)}{\partial B_{t}}\right)-(1-v) \frac{Y_{t}}{N_{h, t}}\right]=\beta_{e} E_{t}\left[\frac{1}{C_{e, t+1}} m^{N} W_{h, t} R_{e, t}\right]
\end{gathered}
$$

Equations (5) and (6) inform about the optimal intertemporal substitution schemes between consumption and demand of the corresponding productive factor. The way $m_{t}^{H}$ and $m^{N}$ enter in each of the optimality conditions shows that the collateral constraint introduces a wedge between the marginal productivity of the input and its price. Whereas credit adjustment costs only distort entrepreneurs' decisions in the transition dynamics, the presence of a borrowing constraint of the type (4) does not only generate inefficiencies in the transition but also in the steady state itself. To have a clear account of this phenomenon, the steady state expressions of (5) and (6) are presented

$$
\begin{aligned}
q & =\frac{v}{\eta}\left(\frac{Y}{H_{e}}\right) \\
W_{h} & =\frac{(1-v)}{\psi} \frac{Y}{N_{h}}
\end{aligned}
$$

where $\eta=\frac{1}{\beta_{e}}\left[1-\frac{m^{H}}{R_{e}}-\beta_{e}\left(1-m^{H}\right)\right]$, and $\psi=\left\{1+m^{N}\left[1-\beta_{e} R_{e}\right]\right\}$. It could be shown that, given the considered lower and upper bounds for $m^{H}$ and $m^{N}$ and the range of values typically proposed in the literature for the discount factors of borrowers and bankers, the following inequalities always hold in the steady state of this economy: $\eta<1$ and, $\psi>1$. Compared to a frictionless economy, in the long-run equilibrium the commercial real estate-to-labor ratio is inefficiently low.

\subsubsection{Bankers}

Let $d_{b, t}$ represent bank dividends (which are fully devoted to final consumption by bankers) in period $t$ and $\beta_{b}<\beta_{h}$. The representative banker seeks to maximize

$$
E_{0} \sum_{t=0}^{\infty} \beta_{b}^{t} \frac{1}{(1-\sigma)} d_{b, t}^{(1-\sigma)}
$$


subject to

$$
\begin{gathered}
B_{t}=K_{b, t}+D_{t} \\
d_{b, t}+K_{b, t}-(1-\delta) K_{b, t-1}=r_{e, t} B_{t-1}-r_{h, t-1} D_{t-1}-\Phi_{b}\left(B_{t}\right)-\varphi\left(d_{b, t}\right) \\
D_{t} \leq \gamma B_{t}
\end{gathered}
$$

Where equations (8), (9) and (10) denote the balance sheet identity, the sequence of cash flow restrictions, and the borrowing constraint of the banker, respectively.

According to (8), bank assets are financed by the sum of bank equity $K_{b, t}$ (also referred to as bank capital) and debt. There is only one type of bank assets; one-period loans which are extended to entrepreneurs. Bank debt is entirely composed of funds borrowed by households in the form of homogeneous one-period deposits. The model assumes full inside equity financing, in the sense that bank equity is solely accumulated out of retained earnings. Formally, the law of motion for bank capital resembles that of Gerali et al. (2010)

$$
K_{b, t}=J_{b, t}-d_{b, t}+(1-\delta) K_{b, t-1}
$$

where $J_{b, t}$ stands for bank net profits and $\delta \in[0,1]$ denotes the fraction of own resources the banker devotes to manage bank capital and to play its role as financial intermediary.

Equation (9) is a flow of funds constraint which states that in each period the banker has to distribute net profits $J_{b, t}$ between dividend payouts $d_{b, t}$ and retained earnings. In the basic model, bank net profits are defined as the difference between the lending spread and the corresponding credit and equity payout adjustment costs. ${ }^{11} r_{e, t}$ and $r_{h, t}$ denote the net interest rates on loans and deposits, respectively. As in Jermann and Quadrini (2012), the model assumes an equity payout adjustment cost of the type

$$
\varphi\left(d_{b, t}\right)=\frac{\kappa}{2}\left(d_{b, t}-d_{b}^{s s}\right)^{2}
$$

where $\kappa \geq 0$ is the payout adjustment cost parameter, and $d_{b}^{s s}$ the long-run payout target

\footnotetext{
${ }^{11} \mathrm{As}$ in the case of the entrepreneur, $\Phi_{b}\left(B_{t}\right)=\frac{\phi_{b}}{2} \frac{\left(B_{t}-B_{t-1}\right)^{2}}{B^{s s}}$ is a quadratic loan portfolio adjustment cost and is assumed to be external to the banker. $\phi_{b} \geq 0$ is the credit adjustment cost parameter.
} 
(steady state). ${ }^{12}$ When $\kappa>0$, this modeling device accounts for the empirical regularity of dividend smoothing. Lintner (1956) found that managers have a dividend payout target and a fixed rate at which dividends should converge towards that target. While remaining agnostic about the underlying factors of dividend smoothing, assuming $\varphi\left(d_{b, t}\right)$ allows to capture the main macroeconomic implications of such phenomenon in a simple manner. At the individual level, bank managers face costs from deviating from a pre-determined payout target. ${ }^{13}$ At the social level, it generates inefficiencies over the cycle ${ }^{14}$.

Expression (10) stipulates that bankers are constrained in their ability to issue liabilities. For a given period $t$, deposits cannot exceed a proportion $\gamma \in[0,1]$ of total assets. Given that this expression is binding in a neighborhood of the steady state, $(1-\gamma)$ can be interpreted as the target capital ratio internally set by bankers.

The optimality condition for this maximization problem can be obtained after having rearranged and substituted in its three first order conditions.

$$
\frac{(1-\gamma)+\frac{\partial \Phi_{b}\left(B_{t}\right)}{\partial B_{t}}}{d_{b, t}^{\sigma}\left[1+\kappa\left(d_{b, t}-d_{b}^{s s}\right)\right]}=\beta_{b} E_{t}\left\{\frac{\left(R_{e, t+1}-\delta\right)-\gamma\left(R_{h, t}-\delta\right)}{d_{b, t+1}^{\sigma}\left[1+\kappa\left(d_{b, t+1}-d_{b}^{s s}\right)\right]}\right\}
$$

Expression (13) stands for the optimality condition for intertemporal substitution between the part of net income devoted to the dividend payout policy (denominator) and that dedicated to the financial intermediation activity (numerator). The engine of the intertemporal activity of bankers is earnings retention. Importantly, bankers endogenously manage the size of their balance sheet and set the growth path of future expected profits (and, thus, of expected dividends) by controlling for retained earnings.

From the perspective of the banker as a consumer, expression (13) can be interpreted as the standard Euler equation for intertemporal substitution of consumption. ${ }^{15}$ The term $\frac{1}{d_{b, t}^{\sigma}\left[1+\kappa\left(d_{b, t}-d_{b}^{s s}\right)\right]}$ refers to the marginal utility of resources devoted to consumption in period $t .^{16}$ The terms in the numerator of each side of the equation account for all the different components involved in the expected gross return on marginal savings (via earnings retention) in period $t$. Recall from equa-

\footnotetext{
${ }^{12}$ See Begenau (2016) for a DSGE model of capital requirements in which banks are subject to this adjustment cost.

${ }^{13}$ An important empirical fact is that markets react negatively (positively) to announcements of dividend decreases (increases). See Allen and Michaely (2003).

${ }^{14}$ The social costs of dividend smoothing take two forms in this model. First, the direct cost in terms of the resources devoted by bankers to deviate from the dividend target, which in the aggregate may be non-negligible. Second, the implicit social welfare cost in terms of increased financial volatility induced by forcing retained earnings to act as the main adjustment variable in the face of shocks that hit bank profits.

${ }^{15}$ Recall that in the basic model bankers are both, owners and managers of the bank. As owners, in each period they receive a dividend payout which is fully devoted to final consumption within the same period.

${ }^{16}$ Which include the dividend payment and the equity payout adjustment cost.
} 
tions $(8)$ and (10) that increasing equity by $(1-\gamma)$ units, automatically implies the borrowing of additional $\gamma$ units of debt and the extension of an extra unit of loans. The latter implies paying a marginal cost for having adjusted the loan portfolio of $\frac{\partial \Phi_{b}\left(B_{t}\right)}{\partial B_{t}}$ in period $t$. Then, it follows that $\left(R_{e, t+1}-\delta\right)$ is the marginal revenue of lending, $\gamma\left(R_{h, t}-\delta\right)$ the marginal cost of issuing debt, and $(1-\gamma)$ the marginal opportunity cost of equity (in terms of foregone marginal utility of dividends). In the optimum the banker is indifferent between devoting an extra unit of profits to paying dividends today and postponing such payment to the next period.

From the lens of the banker as a manager, it is optimal to invest (via earnings retention) up to the point in which the marginal cost of retaining an additional unit of net profits equalizes the marginal revenue of such investment. Expressed in terms of the opportunity cost (foregone marginal utility of dividends), the right-hand side of expression (13) informs about the discounted marginal gross lending spread the banker expects to obtain tomorrow as a consequence of having invested $(1-\gamma)$ units of retained earnings today. ${ }^{17}$

Given the interest rate on deposits, expression (13) determines the equilibrium interest rate on loans. Hence, the assumption by which $\beta_{b}<\beta_{h}$ ensures that in the steady state, $\left(R_{e, t+1}-\delta\right)-$ $\gamma\left(R_{h, t}-\delta\right)>0$.

Equation (13) synthesizes the information of a powerful mechanism for transmission and amplification of shocks that hit bank profits. Absent the possibility of raising capital by issuing new equity (equation 11), the strong preference for dividend smoothing implicit in expressions (7) and (12) implies that the bulk of the adjustment to shocks that hit profits is going to be made via retained earnings. Due to the strong link between equity, loans and deposits (equations 8 and 10), such fluctuations in retained earnings are going to have an impact on the welfare of savers and borrowers through volatile deposits and loans, respectively.

\subsubsection{Macroprudential Authority}

In the baseline scenario, the only policy instrument the prudential authority has at hand is the constant capital requirement implied by equation (10). The regulator is assumed to have full control over the capital adequacy parameter $\gamma$ from equation (10).

Consider an alternative policy scenario in which the capital requirement $\gamma$ is complemented by a simple prudential rule on bank dividends

$$
d_{t}^{*}=\rho_{d}+\rho_{\chi}\left(\frac{x_{t}}{x^{s s}}-1\right)
$$

\footnotetext{
${ }^{17}$ Again, by equations (8) and (10), such decision automatically involves borrowing additional $\gamma$ units of deposits and lending an extra unit of assets.
} 
where $d_{t}^{*}$ is what shall be called the dividend prudential target. This rule comprises a microprudential component, $\rho_{d}$, which is the equity payout targeted by the prudential authority in the absence of financial fluctuations, and a macroprudential component, $\rho_{\chi}\left(\frac{x_{t}}{x^{s s}}-1\right)$, that adjusts to tame the financial cycle. $x_{t}$ is an aggregate the prudential authority closely monitors to detect potential signs of systemic risk and financial instability (e.g., the credit-to-output ratio), and $x^{s s}$ its steady state value. Thus, $\rho_{\chi}$ is the policy parameter that measures the degree of responsiveness of $d_{t}^{*}$ to deviations of $x_{t}$ from its steady state level (e.g., reaction to the so called credit-to-output gap).

As in Angelini, Neri and Panetta (2014), the macroprudential policy rule enters in the corresponding equity adjustment cost function (equation 12) as follows

$$
\varphi^{*}\left(d_{b, t}^{a}\right)=\frac{\kappa}{2}\left(d_{b, t}^{a}-d_{t}^{*}\right)^{2}
$$

where $d_{b, t}^{a}$ refers to the bank dividend payout in the alternative policy scenario. In period $t$, the following inequalities may hold: $d_{b, t} \neq d_{b, t}^{a}$ and $d_{b}^{s s} \neq d_{t}^{*}$, implying $\varphi\left(d_{b, t}\right) \neq \varphi^{*}\left(d_{b, t}^{a}\right)$. Given that such adjustment cost differential would be triggered by policy intervention, the corresponding resources shouldn't be considered as a deadweight loss, but rather as a penalty bankers must pay to the prudential authority for having deviated from $d_{t}^{*}$. In the model, such public resources are transferred within the same period to the non financial sector of the economy. The net subsidy under consideration can be defined as follows

$$
T_{t}=\frac{\kappa}{2}\left[\left(d_{b, t}^{a}-d_{t}^{*}\right)^{2}-\left(d_{b, t}-d_{b}^{s s}\right)^{2}\right]
$$

As it will become more evident in the quantitative exercise, the net subsidy (16) can be positive or negative over the cycle and its size is proportional to the deviation of the representative banker, $d_{b, t}^{a}$, from the dividend prudential target, $d_{t}^{*}$.

Importantly, the transmission of macroprudential dividend regulation in this model mainly takes place through the optimality condition of the representative banker, which now reads

$$
\frac{(1-\gamma)+\frac{\partial \Phi_{b}\left(B_{t}\right)}{\partial B_{t}}}{\left(d_{b, t}\right)^{\sigma}\left[1+\kappa\left(d_{b, t}-d_{t}^{*}\right)\right]}=\beta_{b} E_{t}\left\{\frac{\left(R_{e, t+1}-\delta\right)-\gamma\left(R_{h, t}-\delta\right)}{\left(d_{b, t+1}\right)^{\sigma}\left[1+\kappa\left(d_{b, t+1}-d_{t+1}^{*}\right)\right]}\right\}
$$

Absent a dynamic dividend target, the banker finds optimal to react to exogenous shocks mostly by readjusting the variables that take part in the financial intermediation activity (numerator on 
each side of equation 13). ${ }^{18}$ Under a dividend prudential target within the class (14), the regulator aims at discouraging bankers from making the adjustments via credit supply by means of more responsive bank dividends (denominator on each side of equation 17).

Without prejudice of the merit alternative specifications of dividend regulation may have, the regulatory scheme comprised of equations (14), (15), and (16) has been selected due to its properties, which will be commented upon in the quantitative exercise of this section. ${ }^{19}$

Dividend prudential targets are aimed at mitigating the potential negative macroeconomic effects of adjusting regulatory capital ratios and at enhancing the effectiveness of capital regulation as a macroprudential tool. Thus, it is reasonable to consider an additional policy scenario to asses the functioning of dynamic capital requirements in this model. In order to do so, the debt-to-assets ratio, $\gamma$, is augmented with a cyclical component

$$
\gamma_{t}=\gamma+\gamma_{x}\left(\frac{x_{t}}{x^{s s}}-1\right)
$$

where $\gamma_{x}$ is the macroprudential policy parameter associated to the regulatory capital ratio implied by equation (18), $\left(1-\gamma_{t}\right) . \quad x_{t}$ is the same macroeconomic indicator chosen for policy rule (14). Note that equations (10) and (13) are directly affected by this new policy environment.

\subsubsection{Aggregation and market clearing}

In equilibrium, all markets clear. In the case of the goods market, the aggregate resource constraint dictates that the output produced by entrepreneurs is fully expended in the form of final private consumption, banking investment (i.e., earnings retention), and resources devoted to adjust key financial aggregates.

$$
Y_{t}=C_{t}+K_{b, t}-(1-\delta) K_{b, t-1}+\varphi\left(d_{b, t}\right)+\phi_{b}\left(B_{t}\right)+\phi_{e}\left(B_{t}\right)
$$

where $C_{t}$ denotes the aggregate consumption of the three agent types. Formally, $C_{t}=C_{h, t}+$ $C_{e, t}+d_{b, t}$. Similarly, aggregate demand for housing equalizes supply. Housing supply is specified as a fixed endowment that is normalized to unity.

$$
\bar{H}=H_{h, t}+H_{e, t}
$$

\footnotetext{
${ }^{18}$ In equations (15) and (16), variables under the alternative policy scenario have been denoted with superscript " $a$ " to make clear that the following inequality may hold; $d_{b, t} \neq d_{b, t}^{a}$, for $t=0,1,2$,..For simplicity, such superscript has been omitted in other equations in which it would be applicable, such as expression (17).

${ }^{19}$ Alternatively, a regulatory scheme on bank dividends could be based either on distributed earnings taxation or on a linear restriction on dividend payouts (generally defined as an upper bound for dividend payments in terms of net profits).
} 


\subsection{Quantitative Exercise}

Do dividend prudential targets contribute to financial stability by smoothing the financial cycle? To gain some insights into this matter, this paper analyzes the economy's response to a financial shock under alternative policy scenarios. In particular, the aim of this section is twofold. First, to clearly identify the transmission mechanism through which the proposed policy rule works. Second, to quantitatively assess the potential of dividend prudential targets to tame the credit cycle in the face of collateral shocks.

In order to do so, the paper follows Angelini, Neri and Panetta (2014), who assume the macroprudential authority seeks to minimize an ad hoc loss function with respect to the parameters of the policy rule. In following that approach, there is no attempt in presenting such an objective function as a welfare criterion, but rather as a measure of the potential the proposed policy rule has to prevent the build-up of macro-financial imbalances.

A utility-based welfare analysis will be carried out in section 5 for the extended model.

\subsubsection{Calibration}

The calibration is largely based on Gerali et al. (2010) and Iacoviello (2015). The households' discount factor is set to 0.9943 , implying a steady-state interest rate on deposits slightly above 2 percent $(2.3 \%)$. The discount factor of the entrepreneur is fixed to 0.94 , within the range typically suggested in the literature for constrained consumers. The banker's discount factor, $\beta_{b}$, is chosen to ensure that the steady-state annualized lending rate to the private sector is roughly 5.6 percent, implying an annualized lending spread of $3.4 \%$.

As in Iacoviello (2015), the weight of housing in the household's utility function is set to 0.075 , the elasticity of production with respect to commercial housing, $v$, at 0.05 , the loan portfolio adjustment cost parameter of entrepreneurs and bankers to 0.25 , and the leverage parameter for the bank to 0.9 . The latter implies a capital-asset ratio of 0.1 , implying a positive capital buffer (over the minimum capital requirement of 0.08), as the evidence suggests. As in Jermann and Quadrini (2012), the dividend adjustment cost parameter, $\kappa$, is fixed to 0.426 .

The loan-to-value ratio on housing, $m_{H}$, the intertemporal elasticity of substitution for consumption of bankers, $\sigma$, and the inverse of the Frisch elasticity of labor, $\phi$, are set to standard values of $0.7,1$, and 1.5 , respectively.

The bank capital depreciation rate is calibrated at 0.034 so as to ensure the steady state dividend payout ratio is in the vicinity of 0.6 , as the evidence for the SX7E index suggests. $m_{N}$ is fixed to 0.5 , implying a loan-to-output ratio of 1.9, as in the model estimated for the euro area in Gerali et al. (2010). The autocorrelation coefficient and the standard deviation associated to the collateral shock are obtained from the structural estimation of the same paper. 


\subsubsection{The Transmission Mechanism of Dividend Prudential Targets}

Figure 2 plots the economy's response to a $1 \%$ negative collateral shock in the baseline scenario. Impulse responses are defined in terms of percentage deviations from the steady state. The fall in the loan-to-value ratio reduces the value of commercial real estate as collateral. Entrepreneurs react by decreasing their demand of commercial real estate. Given the fixed supply of real estate, that causes an excess supply which pushes real estate prices downwards. Through the borrowing constraint (equation 4), this overall effect obliges the entrepreneur to obtain less bank credit than before the shock (fall in credit supply).

Due to input complementarities, the decrease in the demand for real estate comes along with a decline in the labor demand. That causes output to decrease and credit demand to shrink. This credit demand effect dominates the supply one during the first quarters after the shock. Thus, the interest rate on loans initially declines.

By way of contrast, and due to a shortfall in the supply for deposits, the interest rate on deposits jumps within the first quarters after the shock. ${ }^{20}$ As a consequence, bank profits fall to gradually recover. Its components, dividends and retained earnings, decrease although the former is less volatile than the latter. In line with the evidence shown in section 2 , the dividend payout ratio is notably countercyclical since the adjustment is mainly borne by retained earnings.

Figure 3 additionally plots the impulse responses to the same shock under the two alternative policy regimes under consideration. The starred line corresponds to an economy in which the macroprudential authority solves the following problem

$$
\arg \min _{\rho_{d}, \rho_{x}} L^{m p}=\kappa_{z} \sigma_{z}^{2} \quad \kappa_{z}>0
$$

where $\sigma_{z}^{2}$ is the asymptotic variance of a macroeconomic indicator of the choice of the regulator. Due to its relevance in macroprudential policy decision-making, $z_{t}$ has been chosen to be the loans-to-output gap. Based in the literature, the preference parameter $\kappa_{z}$ is fixed to 1 . In order to identify the optimal simple rule within the class (14) that solves (19), it has been searched over a multidimensional grid of parameter values, which can be defined as follows. $\rho_{d}\{0-1\}$, $\rho_{x}\{(-150)-150\}$. The choice of the search grid deserves a thorough explanation. First, $\rho_{d}$ refers to the dividend payout targeted by the prudential authority in the steady state. Taking that into account and normalizing the values for $\rho_{d}$ by expressing them in terms of steady state bank profits, it is reasonable to assume that its optimized value will lie somewhere between 0 and 1 ( 0 refers to the case in which all profits are retained and 1 to that in which steady state profits are fully distributed). Second, a wide grid of values for $\rho_{x}$ has been chosen for several reasons. Firstly, the

\footnotetext{
${ }^{20}$ Recall from equations (8) and (10), that for every one-unit decline in credit supply, equity automatically decreases by $(1-\gamma)$ units while debt does it by $\gamma$ units.
} 
dynamics of this policy rule is largely unknown. Secondly, the combination of two strong drivers for dividend smoothing (log utility of bankers and equity adjustment costs) and a somewhat low baseline value for structural parameter $\kappa$, suggests the rule will have to be considerably responsive for bankers to optimally deviate from their long-run target.

There has been searched within the baseline calibration model. The values that correspond to the optimized policy rule are the following: $\rho_{d}=0.54, \rho_{x}=100.23$. The optimal simple rule within the class (14) that solves (19) under full commitment calls for a countercyclical (i.e., $\rho_{x}>0$ ) and highly responsive dividend prudential target and a steady state dividend payout slightly lower than the one targeted by bankers absent any dividend regulation. ${ }^{21}$

As figure 3 makes clear, such rule calls for highly procyclical, relatively more volatile bank dividends. Importantly, now bank dividends (and, thus, bank profits) adjust more gradually towards its steady state level. The influence credit adjustment costs have on the prudential tool through the credit-to-output ratio account for this effect. As a result of this, retained earnings and bank capital are less volatile than in the baseline scenario. The main adjustment variable is no longer retained earnings but dividends. Thus, the hike in the dividend payout ratio becomes less pronounced during the bust phase. Given the linear relationship between equity and loans implied by equations (8) and (10), the policy is effective in taming the credit cycle.

For the sake of comparison between the workings of prudential policy rules (14) and (18), consider a third scenario in which the macroprudential authority solves (19), but this time with respect to the parameters of policy rule (18), $\gamma$ and $\gamma_{x}$. The selected grid of parameter values can be defined in the following manner. $\gamma\{0.85-0.92\}, \gamma_{x}\{(-1)-1\}$. The grid for $\gamma$ implies a sensible range of values for the capital ratio between the minimum capital requirement (i.e., 0.08) and a regulatory capital ratio of 0.15. The grid for $\gamma_{x}$ is based upon the Basel III Accord and has been chosen to asses whether the optimized capital buffer in this model is countercyclical (i.e., $\gamma_{x}<0$ ) or not. The optimized policy rule within the class (14) that solves (19) under full commitment corresponds to: $\gamma=0.899, \gamma_{x}=-0.426 .{ }^{22}$ As shown in figure 3 , this policy (dotted line) smooths credit supply and the loans-to-output gap. ${ }^{23}$

However, the mechanisms triggered by each of the two macroprudential rules under examination are different. Under an optimized dynamic capital requirement, bankers have to meet a lower target capital ratio. Hence, the adjustment in retained earnings to smooth dividends is even more pronounced than in the baseline scenario. Loans volatility is reduced by the relative substitution of equity for debt induced by the countercyclical capital buffer $(\mathrm{CCyB}) .{ }^{24} \mathrm{In}$ contrast, the

\footnotetext{
${ }^{21}$ Recall that the baseline calibration implies a dividend payout ratio of roughly 0.6 .

${ }^{22}$ In order to ensure that I have found a global minimum in each of the two optimization problems, I have selected different tuples of initial conditions. Optimized parameter values remain the same regardless of the initial guess.

${ }^{23}$ Given the objective of the prudential authority (i.e., to solve (19)), the optimized rule within the class (18) mainly operates through its cyclical component, $\gamma_{x}$.

${ }^{24}$ Note that in this model, during the bust phase, the action of the CCyB by which the target capital ratio
} 
credit smoothing attained through the optimized dividend prudential target builds on less volatile retained earnings and bank equity.

Table 1 summarizes the results of the solution to problem (19), for a variety of arguments for the loss function, $\sigma_{z}^{2}$. Part (i) of the table presents the prudential losses for a variety of loss functions, under the baseline scenario. Part (ii) reports the results of the solution to the mentioned problem when optimizing with respect to $\rho_{d}$ and $\rho_{x}$. Part (iii) presents the results of the solution to the same problem but only when having optimized with respect to $\rho_{x}$. Several conclusions are worth mentioning. First, the kind of dividend-based macroprudential rule that promotes financial stability is robust across macroeconomic indicators, $z_{t}$. The optimized rule within the class (14) that smooths the financial cycle is countercyclical and notably responsive. ${ }^{25}$ Second, dividend prudential targets aimed at promoting financial stability mainly operate through its cyclical component. ${ }^{26}$

The quantitative exercise helps to identify several properties of the optimized dividend prudential target. (i) It is effective in smoothing the credit cycle by means of a countercyclical, highly responsive dividend prudential target that ensures the main burden of the adjustment is no longer borne by retained earnings. (ii) It is flexible in the sense that it allows bankers to optimally deviate from the target. ${ }^{27}$ As noted in figure 3, bankers optimally choose dividends to be considerably less volatile than the dividend prudential target. (iii) It is associated to a sanctions regime that acts as an insurance scheme for the real economy. ${ }^{28}$ (iv) It mainly operates through its cyclical component, ensuring that long-run dividend payouts remain unaffected. ${ }^{29}$ (v) As shown in figure 3 , it is more effective than a standalone optimized capital rule of the type (18) in smoothing the credit cycle (measured by the asymptotic variance of the credit gap and the credit-to-output gap), as well as in promoting bank soundness (proxied by the asymptotic variance of bank equity).

descends, automatically implies an increase in the leverage ratio.

${ }^{25}$ Interestingly, when optimizing only with respect to $\rho_{x}$, the parameter value that solves problem (19) coincides for most of the considered macroeconomic indicators, $z_{t},\left(\rho_{x}=54.802\right)$.

${ }^{26}$ Note that the differences in terms of macroprudential losses between solving the optimization problem with respect to $\rho_{d}$ and $\rho_{x}$, and solving it only with respect to $\rho_{x}$ are small. Due to the fact that the considered policy induces higher volatility in the resources devoted to bank dividend policies, its potential to smooth output is more limited. As it will be shown in section 5, this does not conflict with the potential of the dividend-based rule for improving social welfare.

${ }^{27}$ In the model, this property is important to ensure that a balance between the social benefits from credit smoothing and the cost for bankers of higher dividend volatility is optimally stricken. In practice, this kind of flexibility could be decisive in order for the regulatory scheme to be implementable. Allowing for deviations permits bankers to manage additional risks which are not considered in this model (e.g., the risk of a severe fall in the equity price in response to a regulatory induced cut in dividends).

${ }^{28}$ As noted in figure 3, the net subsidy (equation 16) associated to the optimized dividend prudential target is countercyclical. That is to say, their recipients (households and/or entrepreneurs) benefit from a positive payment when the marginal utility of their consumption is relatively high.

${ }^{29}$ This result has important implications. Optimizing (regulating) only with respect to the cyclical component of the dividend-based rule ensures that in the steady state: (i) the dividend payout and the welfare of bankers are not negatively affected, and (ii) equations (15) and (16) are equal to zero. 



\section{Extended Model}

In order to improve the dynamics of the model and its mapping to the data, the model is extended in three main directions. First, a second type of household with a lower subjective discount factor is incorporated into the model. Thus, two types of households coexist, one being net savers (patient households) and the other one being net borrowers (impatient households). In equilibrium bank loans are now extended to credit constrained households and entrepreneurs. Second, the model allows for physical variable capital. Capital-good-producers sell their output to entrepreneurs, who use it as an input in the productive process. Third, additional shocks are considered to allow for a more comprehensive analysis of dividend prudential targets.

Importantly, in this version of the model households are the owners of all existing firms: finalgood-producing firms (entrepreneurs), banks and capital-good-producing firms. As in Clerc et al. (2015) and Mendicino et al. (2018), this approach permits to restrict the welfare analysis to households without neglecting any consumption capacity generated in the economy.

This section only discusses the main changes the extended model incorporates, with respect to the basic version under the baseline scenario. The full set of equilibrium equations that includes the policy block, can be found in Appendix B.

\subsection{Overview of the Model}

\subsubsection{Households}

Impatient households discount the future more heavily than patient ones, implying $\beta_{i}<\beta_{p}$. In the extended model the representative household maximizes

$$
E_{0} \sum_{t=0}^{\infty} \beta_{\varkappa}^{t}\left[\varepsilon_{t}^{z} \log C_{\varkappa, t}+\varepsilon_{t}^{h} j \log H_{\varkappa, t}-\frac{N_{\varkappa, t}^{1+\phi}}{(1+\phi)}\right]
$$

where $\varkappa=p, i$ denotes the type of household the problem refers to. $\varepsilon_{t}^{z}$ and $\varepsilon_{t}^{h}$ are exogenous preference shocks for consumption and housing demand, respectively. Shocks in the extended model have the same properties as the one presented in the basic version.

Patient households (net savers) In the case of patient households, the maximization of (20) is restricted to the sequence of budget constraints

$$
C_{p, t}+D_{t}+q_{t}\left(H_{p, t}-H_{p, t-1}\right)=R_{d, t-1} D_{t-1}+W_{t} N_{p, t}+\omega_{b}\left(d_{b, t}+T_{t}\right)+\omega_{e} d_{e, t}
$$

where $d_{e, t}$ refers to earnings distributed by entrepreneurs. $\omega_{b}$ is the fraction of banks owned 
by patient households and $\omega_{e}$ the proportion of entrepreneurial firms owned by the same agent type. Note that the net subsidy they receive from the prudential authority is proportional to the stake of banks they own. This is relevant for the alternative policy scenario, in which the following inequality may hold, $T_{t} \neq 0$. That is to say, the degree of insurance received by households is assumed to be proportional to their exposure to the increased bank volatility triggered by the dividend prudential target.

Impatient households (net borrowers) As a net borrower, the representative impatient household is restricted not only by a sequence of budget constraints but also by a borrowing limit.

$$
\begin{gathered}
C_{i, t}+R_{i, t-1} B_{i, t-1}+q_{t}\left(H_{i, t}-H_{i, t-1}\right)+\Phi_{i}\left(B_{i, t}\right)=B_{i, t}+W_{t} N_{i, t}+\left(1-\omega_{b}\right)\left(d_{b, t}+T_{t}\right)+\left(1-\omega_{e}\right) d_{e, t} \\
B_{i, t} \leq m_{i, t}^{H} E_{t}\left[\frac{q_{t+1}}{R_{i, t}} H_{i, t}\right]
\end{gathered}
$$

Each period, impatient households devote their available resources in terms of wage earnings, loans, distributed earnings, and the corresponding net subsidy; to consume, repay their debt, demand housing real estate and adjust their loan portfolio. As it was the case for entrepreneurs in the basic model, the borrowing capacity of impatient households is tied to the expected value of their housing property.

\subsubsection{Entrepreneurs}

Let $\Lambda_{0, t}^{e}=\left[\omega_{e} \beta_{p} \frac{\lambda_{t+1}^{p}}{\lambda_{t}^{p}}+\left(1-\omega_{e}\right) \beta_{i} \frac{\lambda_{t+1}^{i}}{\lambda_{t}^{i}}\right]$ be the stochastic discount factor of entrepreneurs (managers), with $\lambda_{t}^{p}$ and $\lambda_{t}^{i}$ being the Lagrange multipliers of the patient and impatient households' optimization problems, respectively. Then, the representative entrepreneur maximizes

$$
E_{0} \sum_{t=0}^{\infty} \Lambda_{0, t}^{e} \log d_{e, t}
$$

subject to the sequence of budget constraints, the available technology and the corresponding borrowing limit

$$
d_{e, t}+R_{b, t} B_{e, t-1}+q_{t}^{k}\left[K_{e, t}-\left(1-\delta^{k}\right) K_{e, t-1}\right]+W_{t} N_{t}+\Phi_{e}\left(B_{e, t}\right)=Y_{t}+B_{e, t}
$$




$$
\begin{gathered}
Y_{t}=A_{t} K_{e, t-1}^{\alpha} N_{t}^{1-\alpha} \\
B_{e, t} \leq m_{e, t}^{K} E_{t}\left(\frac{q_{t+1}^{k}}{R_{e, t+1}} K_{e, t}\right)-m^{N} W_{t} N_{t}
\end{gathered}
$$

Note the three differences of this optimization problem compared to the one presented in the previous section. First, Owners and managers of final-good-producing firms are no longer the same agent. Second, the production function no longer includes commercial real estate as an input but variable physical capital. Third, entrepreneurs also face a technology shock, $A_{t}$.

\subsubsection{Bankers}

Similarly, $\Lambda_{0, t}^{b}=\left[\omega_{b} \beta_{p} \frac{\lambda_{t+1}^{p}}{\lambda_{t}^{p}}+\left(1-\omega_{b}\right) \beta_{i} \frac{\lambda_{t+1}^{i}}{\lambda_{t}^{i}}\right]$ stands for the stochastic discount factor of bankers. Bank managers seek to maximize

$$
E_{0} \sum_{t=0}^{\infty} \Lambda_{0, t}^{b} \frac{1}{(1-\sigma)} d_{b, t}^{(1-\sigma)}
$$

subject to a balance sheet identity, a sequence of cash flows restrictions, and a borrowing constraint, respectively

$$
B_{i t}+B_{e, t}=K_{t}+D_{t}
$$

$d_{b, t}+K_{b, t}-(1-\delta) K_{b, t-1} \varepsilon_{t}^{k b}=r_{e, t} B_{e, t-1}+r_{i, t-1} B_{i, t-1}-r_{d, t-1} D_{t-1}-\Phi_{b e}\left(B_{e, t}\right)-\Phi_{b i}\left(B_{i, t}\right)-\varphi\left(d_{b, t}\right)$

$$
D_{t}=\gamma_{i} B_{i, t}+\gamma_{e} B_{e, t}
$$

As for the case of entrepreneurs, in the extended model there is a separation between ownership and management of banks. The loan portfolio is composed of two types of assets, $B_{i, t}$ and $B_{e, t}$, which may differ in two aspects: (i) their associated capital requirements, $\gamma_{i}$ and $\gamma_{e}$, and (ii) their respective adjustment cost parameter. $\varepsilon_{t}^{k b}$ denotes a shock to bank capital. 
Importantly, the solution to this optimization problem yields two optimality conditions analogous to expression (13), one for each asset class.

\subsubsection{Capital goods producers}

At the beginning of each period, capital producers demand an amount $I_{t}$ of final good from entrepreneurs, which combined with the available stock of capital, allows them to produce new capital goods. Capital producers choose the trajectory of net investment in variable capital, $I_{t}$, that maximizes

$$
E_{0} \sum_{t=0}^{\infty} \Lambda_{0, t}^{e}\left\{q_{k, t} I_{t}-\left[I_{t}+\frac{\psi_{k}}{2 \delta_{k}}\left(\frac{I_{t}}{K_{e, t-1}}-\delta_{k}\right)^{2} K_{e, t-1}\right]\right\}
$$

where $\frac{\psi_{k}}{2 \delta_{k}}\left(\frac{I_{t}}{K_{e, t-1}}-\delta_{k}\right)^{2} K_{e, t-1}$ is an adjustment cost function they have to face when producing new capital goods. The maximization of (32) permits to derive a market price for capital, $q_{k, t}$, which is relevant to determine the collateral value of entrepreneurs in the extended model

$$
q_{k, t}=1+\frac{\psi_{k}}{\delta_{k}}\left(\frac{I_{t}}{K_{e, t-1}}-\delta_{k}\right)
$$

The usual law of motion for physical capital holds

$$
K_{e, t}=I_{t}+\left(1-\delta_{k}\right) K_{e, t-1}
$$

\subsubsection{Aggregation and market clearing}

By the Walras' law, all markets clear . The aggregate resource constraint of the economy represents the equilibrium condition for the final goods market.

$$
Y_{t}=C_{p, t}+C_{i, t}+q_{t}^{k} I_{t}+K_{b, t}-(1-\delta) K_{b, t-1} \varepsilon_{t}^{k b}+A d j_{t}
$$

where the term $A d j_{t}$ corresponds to the sum of all resources dedicated in the economy to adjust loans, bank dividends, and physical capital in period $t$. Similarly, in equilibrium labor demand equals total labor supply,

$$
N_{t}=N_{p, t}+N_{i, t}
$$

Even if loans to impatient households and to entrepreneurs may be related to some external differences, they are homogeneous across agents. Thus, in equilibrium 


$$
B_{t}=B_{i, t}+B_{e, t}
$$

In equilibrium, the housing market clears

$$
\bar{H}=H_{p, t}+H_{i, t}
$$





\section{Quantitative Analysis}

\subsection{Calibration}

The model is calibrated to quarterly euro area data for the period 2002:I-2018:II, based on certain key steady-state values and ratios and taking into account several parameter values that have become standard in the business cycle literature.

First, several parameters are set following convention. Some of them are standard in the literature. Some others are based on papers in the field of macro-finance. Both, the inverse of the Frisch elasticity of labor and the banker's intertemporal elasticity of substitution, are set to a value of 1 . The depreciation rate of physical capital $\delta_{k}$ and the capital share in final-good-production $\alpha$ are fixed to standard values of 0.025 and 0.25 , respectively, thereby allowing consumption-to-GDP and investment-to-GDP to match euro area empirical ratios for the considered period of 0.76 and 0.21 , respectively. Loan-to-value ratios on housing, and physical capital are set to 0.7 and 0.25 , respectively. These values are based on data of the big four euro area economies and coincide with those presented in Gerali et al. (2010), and Quint and Rabanal (2014), among others. The adjustment cost parameter values for loans coincide with those obtained in the structural estimation by Iacoviello (2015). Adjusting loans to households is costlier than making changes in the corporate loans portfolio. That contributes to the former being less volatile than the latter, as implied by the second moments on euro area bank loans. ${ }^{30}$ As in Jermann and (2012), the equity payout cost parameter $\kappa$ is set to 0.426 , and is consistent with the smoothing of dividends observed in figure 1(b). ${ }^{31}$ Based on the calibration proposed in other papers of the literature (see, e.g., Christensen and Dib 2008, and Mendicino and Punzi 2010), the investment cost parameter $\psi_{k}$ is fixed to 0.5 .

Second, the rest of parameters are calibrated by using steady state targets. The patient households' discount factor, $\beta_{p}=0.9943$, is chosen such that the annual interest rate equals $2.3 \%$. The impatient households' discount factor is set to 0.95 , in order to generate an annualized bank spread of $3.4 \%{ }^{32}$ Patient households are assumed to own all the entrepreneurial and capital-producing firms of the economy, $\omega_{e}=1$, while impatient households own all the banks, $\omega_{p}=0$. This assumption is based on the following reasons. (i) They are chosen to match a corporate loans-to-GDP

\footnotetext{
${ }^{30}$ For the period under consideration, relative volatily of non financial corporate loans (2.3905) is larger than that of household loans(0.8089).

${ }^{31}$ Importantly, the increased relative volatility of bank dividends induced by dividend prudential targets should affect the value of parameter $\kappa$. For that reason, the welfare effects of the proposed rule are evaluated for alternative values of $\kappa$ in the robustness checks exercise presented in section 5 .

${ }^{32}$ In order to compute the annualized bank spread, $\left(r_{b}^{s s}-r_{d}^{s s}\right), r_{b}^{s s}$ has been defined as the average of the steady state rates on household and corporate loans, each of them weighted by the proportion of total loans it represents. Steady state interest rates are the only targets that have not been obtained from updated euro area data but from the constructed series in Gerali et al. (2010).
} 
ratio of $175.8 \%$ and a household loans-to-GDP ratio of $214 \%$, respectively. (ii) It permits to limit the welfare analysis to two types of agents (henceforth referred to as savers and borrowers) while fully separating by agent types the two key sources of business cycle costs triggered by optimized dividend prudential targets. ${ }^{33}$ The real estate wealth-to-annual output of savers and borrowers is chosen as the target ratio to set their respective weights on housing utility of, $j_{p}$ and $j_{i}$.

With regards to bank parameters, it shall be proceeded as follows. The depreciation rate of bank capital $\delta$ is set to 0.038 , which is consistent with a payout ratio of 0.563 , in line with the evidence of the SX7E banks' index presented in section 2. Note that after having rearranged in the steady state expression of equation (11)

$$
\frac{d_{b}}{J_{b}}=1-\frac{\delta K_{b}}{J_{b}}
$$

from which the influence parameter $\delta$ has on the steady state payout ratio becomes evident. The calibrated values of the complementaries of capital requirements on household loans $\gamma_{i}$ and corporate loans $\gamma_{e}$ are obtained by solving a system of two linear equations

$$
\begin{gathered}
0.895=\gamma_{i} \frac{B_{i}}{B}+\gamma_{e} \frac{B_{e}}{B} \\
\left(1-\gamma_{e}\right)=2.1176\left(1-\gamma_{i}\right)
\end{gathered}
$$

Equation (39) is the result of equating the steady state leverage ratio to 0.895 after having normalized expression (31) to total loans. Its interpretation is straightforward. The equilibrium capital requirement is a weighted average of the two sectorial capital requirements, $\left(1-\gamma_{e}\right)$ and $\left(1-\gamma_{i}\right)$, and it has been set to 0.105 . Such value has been chosen for empirical and regulatory reasons. (i) It is similar to the pre-crisis historical average of regulatory capital ratios. According to existing capital legislation, the authority cannot impose any restriction on dividend payouts as long as the bank meets the minimum capital requirement (0.08) plus a conservation buffer of 0.025 .

Expression (40) indicates that the capital requirement on corporate loans is slightly more than two times that on household loans. This is exactly the same proportion held by these two sectorial ratios according to the IRB-based calibration presented in Mendicino et al. (2018). For simplicity, a $100 \%$ risk weight has been assumed for each of the two asset types. ${ }^{34}$

\footnotetext{
${ }^{33} \mathrm{As}$ it will be discussed in the welfare analysis that follows, two negative welfare effects induced by dividendbased rules have to be weighted with the positive effects derived from financial smoothing. On the one hand, bank owners suffer from an increased volatility in bank dividends. On the other hand, entrepreneurial-firm owners face a "loan portfolio readjustment effect" by which supply for corporate loans tends to be partially substituted for household loans due to the higher adjustment cost parameter and capital requirement they are associated to.

${ }^{34}$ This assumption is reasonable. As the Capital Requirements Regulation (EU) stipulates, exposures to corpo-
} 
As in the basic model, all parameters related to the autorregressive processes followed by the six shocks present in this extended version of the model correspond to the estimates proposed in Gerali et al. (2010).

Table 2 reports all the baseline parameter values of the model. Table 3 offers an overview of selected target ratios that have been considered when calibrating the model.

\subsection{Welfare Analysis}

This section analyzes the main welfare consequences of complementing capital requirements with a dividend prudential target. Consider the expected life-time utility of savers and borrowers as the welfare criterion

$$
V_{0}^{\varkappa}=E_{0} \sum_{t=0}^{\infty} \beta_{\varkappa}^{t} U\left(C_{\varkappa, t}, H_{\varkappa, t}, N_{\varkappa, t}\right)
$$

with $\varkappa=p, i$. The model is solved by using second-order perturbation techniques. Unconditional lifetime utility is computed as the theoretical mean based on first order terms of the second-order approximation to the nonlinear model, resulting in a second-order accurate welfare measure (see e.g. Kim, Kim, Schaumburg, and Sims 2008). This approach ensures that the effects of aggregate uncertainty are taken into account.

Figure 4 plots the welfare effects of changing each of the two policy parameter values in a policy rule of the type (14) while keeping the other fixed at its baseline value. Two conclusions are worth noting. First, the welfare impact of varying $\rho_{d}$ is negligible for both types of agents and there is no subset of values for such parameter which is welfare-improving for both of them. ${ }^{35}$ Second, there is a considerable range of $\rho_{x}$ values for which increasing the policy parameter implies a Pareto improvement with respect to the baseline case $\left(\rho_{x}=0\right)$. Consequently, in the remainder of the exercise the attention is only focused on the welfare effects of changing $\rho_{x}$ while keeping $\rho_{d}$ at the baseline steady state value of the dividend payout. ${ }^{36}$

Interestingly, figure 4 makes clear that each agent class face a different trade-off, when being exposed to changes in $\rho_{x}$. Higher values of $\rho_{x}$ are associated to less volatile financial aggregates

rates with an "average" credit rating or for which no credit assesment is available, shall be assigned a $100 \%$ risk weight. Unless certain conditions are met, exposures fully secured by a mortgage on immovable property shall also be assigned a risk weight of $100 \%$.

${ }^{35}$ With regards to the welfare effects of changing $\rho_{d}$, this result holds even when simultaneously varying $\rho_{d}$ and $\rho_{x}$

${ }^{36}$ Recall from section 3 that this assumption has little costs but very important benefits. The cost is little because dividend prudential targets aimed at smoothing financial aggregates mainly operate through its cyclical component. The benefits are substantial because it guarantees that in the steady state: (i) the bank dividend payout remains unaffected, and (ii) the net subsidy effectively acts as an insurance scheme for the real economy. 
(including deposits and aggregate loans), which improves welfare of savers and borrowers.

However, increasing $\rho_{x}$ is not free of charge. A more responsive dividend prudential target leads to a higher bank dividend volatility, that negatively affects borrowers' welfare (as bank owners). In addition, changes in $\rho_{x}$ modify the optimal composition of the banker's loan portfolio. Given that corporate loans are subject to higher capital requirements and a higher adjustment cost parameter, a countercyclical dividend prudential target yields a "loan portfolio readjustment effect" by which bankers tend to increase the weight of household loans (in their balance sheet) at the expense of corporate ones. Such effect has a negative impact on savers' welfare (as owners of entrepreneurial firms).

Next, a normative approach is adopted to define a measure of social welfare and maximize it with respect to $\rho_{x}$ in order to quantify the welfare gains of introducing an optimized dividend prudential rule. As in Schmitt-Grohe and Uribe (2007), welfare gains of agent type " $\varkappa$ " are defined as the implied permanent differences in consumption between two different scenarios. Formally, consumption equivalent gains can be specified as a constant $\lambda_{\varkappa}$, that satysfies

$$
E_{0} \sum_{t=0}^{\infty} \beta_{\varkappa}^{t} U\left(C_{\varkappa, t}^{a}, H_{\varkappa, t}^{a}, N_{\varkappa, t}^{a}\right)=E_{0} \sum_{t=0}^{\infty} \beta_{\varkappa}^{t} U\left[\left(1+\lambda_{\varkappa}\right) C_{\varkappa, t}^{b}, H_{\varkappa, t}^{b}, N_{\varkappa, t}^{b}\right]
$$

where superindices $a$ and $b$ refer to the alternative policy scenario (optimized prudential rule) and the baseline case, respectively. In addition, social welfare is defined as a weighted average of the expected lifetime utility of each agent class. Similar to the approach followed in Mendicino et al. (2018), social welfare maximization is subject to certain conditions. The solution: (i) must be a Pareto improvement relative to the baseline scenario, and (ii) it has to yield the same consumption equivalent gains for savers and borrowers, given a pre-set grid of values for $\rho_{x}$. Based on the results from section 3 , such grid is set as follows. $\rho_{x}\{0-80\}$. Formally, the optimization problem under consideration reads

$$
\begin{gathered}
\arg \max _{\rho_{x}} V_{0}=\zeta V_{0}^{p}+(1-\zeta) V_{0}^{i} \\
\text { s.t. } \quad \lambda_{p}=\lambda_{i} \\
\lambda_{p} \geqslant 0, \lambda_{i} \geqslant 0
\end{gathered}
$$

where $\zeta \in[0,1]$ is the weight of patient households' welfare and the combination of the two restrictions implies that the last two inequalities must hold as strict inequalities. Problem (43) is also subject to all the competitive equilibrium conditions of the extended model. ${ }^{37}$

\footnotetext{
${ }^{37}$ In particular, the only difference between the approach followed in Mendicino et al. (2018) and the one followed
} 
For the particular case of log preferences, unconditional welfare gains can be computed analytically

$$
\lambda_{\varkappa}=\exp \left[\left(1-\beta_{\varkappa}\right) E\left(V_{0}^{\varkappa, a}-V_{0}^{\varkappa, b}\right)\right]-1
$$

where $V_{0}^{\varkappa, a}$ and $V_{0}^{\varkappa, b}$ refer to the unconditional welfare of agent type " $\varkappa$ " in the policy and the baseline scenario, respectively. The optimized prudential rule within the class (14) that solves (43) is associated to $\rho_{x}=67.495$, and $\lambda_{\varkappa}=0.001863$.

Table 4 reports the main results of shutting down, one-by-one, each of the shocks. The differences in welfare gains generated by shutting down a particular shock vary across shocks. This is so because the welfare trade-offs savers and borrowers experience, vary across shocks. Figure 5 plots the welfare impact of changing $\rho_{x}$ for each agent class under the different shock scenarios considered in table 4. Some results are worth commenting. Given the solution to problem (43), the wedge in welfare gains created between savers and borrowers when shutting down bank equity and housing preference shocks is relatively notable. To some extent, this is the case due to the relatively large size of these shocks. This is in line with other estimated DSGE models for the euro area economy (see, e.g., Gerali et al. 2010). Table 4 and figure 5 make clear, that the presence of the optimized policy rule in the face of bank equity shocks is a key source of welfare gains for borrowers. Given the linearity between equity and loans, these shocks generate large fluctutations in credit that make the proposed rule particularly effective in reducing loans volatility. That is the reason why, in this case, the "credit smoothing effect" dominates the induced dividend volatility suffered by borrowers (net welfare gains), while the "loan portfolio readjustment effect" is the predominant force in the trade-off faced by savers (net welfare losses). The opposite occurs with housing preference shocks. The optimized policy rule is welfare decreasing for borrowers due to a dominance of the "bank dividend response effect" whereas it is increasing for savers due to a predominant "deposits smoothing effect".

Importantly, by construction of the model the volatility of housing demand and labor is always identical across agent types. ${ }^{38}$ Thus, the bulk of the differences in welfare gains that arise between the two agent types when shutting down each of the shocks, shall be attributed to the welfare effects induced by the optimized policy rule through final consumption.

in this paper is that they search over the grid $\zeta \in[0,1]$ to find the value of the savers' welfare weight that solves the problem while this paper maximizes with respect to the policy parameter, $\rho_{x}$. By construction, given the approach followed here, social welfare gains are going to coincide with those of savers and borrowers regardless of the value $\zeta$ takes.

${ }^{38}$ The assumptions that are behind this result are homogeneity of labor input and fixed housing supply. 


\subsubsection{Welfare Effects and Capital Requirements}

Angeloni and Faia (2009 and 2013), analyze optimized monetary policy rules under alternative Basel regimes. Inspired in their approach, this paper examines the welfare effects of optimized dividend-based macroprudential rules under alternative capital scenarios.

Microprudential Capital Regulation Absent a countercyclical dividend prudential target (baseline scenario), in this model bankers optimally respond to increases in the capital requirement by restricting credit supply. From optimality condition (13), it follows that a higher capital requirement $(1-\gamma)$ in the left-hand side of the equation has to go hand in hand with an increase in the discounted marginal lending spread. The implied reduction in the debt-to-assets ratio does not account for the entire adjustment and bankers optimally reduce their credit supply to induce an increase in their loans rate. In a higher capital requirements scenario, bankers retain more earnings and benefit from an increased marginal lending spread. That allows them to attain a higher and smoother dividend payout at the expense of a more volatile and restricted credit supply.

Table 5(i) reports the welfare gains from increasing the capital ratio by 1.5 percentage points (from 0.105 to 0.12 ) under two different scenarios in terms of dividend regulation. In the first case, the hike in the capital ratio occurs absent any dividend regulation. Savers and borrowers suffer welfare losses induced by a more restrictive and volatile credit supply. Note, however, that the losses experienced by savers are considerably larger than those suffered by borrowers. As bank owners, borrowers benefit from higher and smoother dividend payouts, an effect that partially compensates the impact of the mentioned decline in loans supply. In the second case, the increase in the capital requirements is combined with the adoption of the dividend prudential target that solves (43) under the baseline capital scenario (i.e., $\gamma=0.895$ ). The loans and deposits smoothing effect generated by the dividend-based rule helps in moderating the welfare losses experienced by savers. The combination of a higher dividend payout and a smoother credit supply ensures that borrowers benefit from the macroprudential policy mix.

The remainder of table 5 reports the welfare gains generated by the proposed policy rule under alternative capital scenarios, with and without reoptimizing with respect to $\rho_{x} .{ }^{39}$ In particular, table 5(ii) evaluates the welfare implications of solving problem (43) for two capital scenarios alternative to the baseline (i.e., $\gamma=0.895) .{ }^{40}$ Not surprisingly, the optimized countercyclical

\footnotetext{
${ }^{39}$ There is an important difference between part (i) and parts (ii) and (iii) of table 5 which may not be noticeable in terms of reporting. In part (i) the capital ratio differs between the "alternative" and the "baseline scenario", whereas in parts (ii) and (iii) do not.

${ }^{40}$ The three considered capital scenarios (including the baseline) are inspired in the Basel III Accord. 0.08 refers to the minimum capital requirement. Adding the conservation buffer (0.025) to it yields a capital ratio of 0.105 . As of November 2018, all euro area G-SIBS were required a surcharge lying between 0.01 and 0.02 . For that reason, the paper considers a third scenario whith a capital adequacy ratio of 0.12 .
} 
responsiveness of the dividend prudential target increases with the capital requirement. Higher capital ratios are associated to lower and more volatile credit supply. Thus, they increase the potential of dividend prudential targets to improve welfare. As noted in table 5(iii), this is particularly true for the case of borrowers. Given a pre-set value for $\rho_{x}$ that implies a countercyclical and sufficiently responsive dividend prudential target (e.g., $\rho_{x}=67.495$ ), increases in the capital ratio have particularly positive effects on the welfare of impatient households. This is so because they benefit from an improved trade-off. Given that the dividend-based rule is responsive enough so as to notably smooth loans, higher capital ratios induce higher dividend payouts and contribute to offset the dividend volatility generated by the policy rule under consideration.

Macroprudential Capital Regulation Given the properties of dividend prudential targets as a macroprudential tool, it is relevant to also investigate its interactions with the macroprudential component of existing capital regulation, the so-called countercyclical capital buffer (CCyB). Table 6 summarizes the welfare gains from solving problem (43) with respect to macroprudential policy parameters $\rho_{x}$ and $\gamma_{x}$ (part (i)), as well as from optimizing only with respect to $\gamma_{x}$, while taking $\rho_{x}$ at its benchmark optimized value, 67.495 (part (ii) ${ }^{41}$ 42. Several conclusions can be drawn from the analysis. The optimized macroprudential toolkit comprises a joint capital-and-dividend based countercyclical regulation (i.e., $\rho_{x}>0$, and $\gamma_{x}<0$ ). As shown in figure 6 , if the dividend prudential target is countercyclical and sufficiently responsive, the value of $\gamma_{x}$ that maximizes the welfare of savers and borrowers is in the vicinity of -0.5. ${ }^{43}$ Such a countercyclical capital buffer allows savers and borrowers to benefit from an enhanced trade-off favoured by the dividend-based rule.

Figure 7 confirms that both macroprudential rules are mutually reinforcing. Each of them are effective on their own in smoothing the credit cycle, as well as output, employment and housing demand. ${ }^{44}$ Nonetheless, the jointly optimized rule, that results from solving problem (43) with respect to $\rho_{x}$ and $\gamma_{x},(D P T+C C y B)$, permits the economy to benefit from welfare gains (table $6($ ii) ) and smoothed levels of key economic and financial variables (figure 7) which cannot be attained by any of the two macroprudential tools on their own.

\footnotetext{
${ }^{41}$ Based on previous results of this model, there has been searched over the multidimensional grid $\rho_{d}\{(-1)-0\}$, $\rho_{x}\{0-80\}$.

${ }^{42}$ In this case, there is no optimized policy parameter value/s for which welfare gains are identical between patient and impatient households. Hence, the paper reports the results of macroprudential policies that individually maximize savers and borrowers' welfare.

${ }^{43}$ Interestingly, such value is similar to the one that minimizes the asymptotic variance of the credit-to-output ratio in the basic model, as reported in section 3.

${ }^{44}$ Recall, however, that the potential of dividend prudential targets to smooth output in this model is more limited, since the associated trade-offs households have to face are mainly filtered through final consumption.
} 


\subsection{Robustness Checks}

In practice, prudential authorities base their macroprudential policy decisions on the developments of a wide range of indicators, which include not only the credit-to-output gap, but also other credit gaps and real estate prices, among others. Moreover, the introduction of a dividend prudential target can potentially affect certain structural parameters, especially the dividend adjustment cost parameter $\kappa$.

For these reasons, this paper investigates the robustness of the main welfare results to alternative macroeconomic indicators, $x_{t}$, as well as to changes in parameter $\kappa$. Table 7 and figures 8 and 9 summarize the main findings. With regards to alternative values for $\kappa$ within a sensible range, the shape of saver's lifetime utility as a function of this parameter remains unchanged (see figure 8). The required value of $\rho_{x}$ to reach certain welfare level decreases with parameter $\kappa$, but attainable welfare gains remain unchanged. The case of borrowers is slightly different, since the trade-off they face moderately worsens with $\kappa$. This result does not come as a surprise since bank owners are those who borne the direct cost of adjusting dividends. Therefore, as $\kappa$ increases, the value of $\rho_{x}$ that solves problem (43) and the associated welfare gains decline.

As regards to selecting alternative macroeconomic indicators, $x_{t}$, similar conclusions can be reached. The shape of saver's unconditional welfare as a function of $x_{t}$ is robust across indicators. However, the trade-off faced by borrowers is more sensitive to changes in the macroeconomic aggregate, $x_{t}$.

In a nutshell, although quantitative differences may arise, the main conclusions of this exercise are very robust across calibrated values of key parameters and across alternative specifications of policy scenarios. Countercyclical dividend prudential targets induce welfare gains for savers and borrowers through their smoothing effect on financial aggregates. ${ }^{45}$

\footnotetext{
${ }^{45}$ It is worth highlighting that this conclusion relies on the assumption by which bank owners are compensated with the net subsidy specified in equation (16). Absent such assumption, there is no guarantee that bank owners (in this case, borrowers) would benefit from a countercyclical dividend prudential target in the considered quantitative exercise. This result has two important implications: (i) the main welfare cost of dividend prudential targets relates to the volatility they induce in bank dividends, and (ii) the role played by the proposed sanctions regime as an insurance scheme is crucial to understand the main welfare results of the quantitative exercise.
} 


\section{Conclusion}

The evidence on euro area bank dividends and earnings suggests there is a link between payout policies and the adjustment mechanisms through which bankers opt to meet their target regulatory capital ratios. When shocks hit bank profits, managers adjust retained earnings to smooth dividends. This generates bank equity and credit supply volatility.

This paper develops a DSGE model that features a banking sector and certain financial frictions that account for this empirical phenomenon. Then, it defines a dividend-based regulatory scheme that is shown to be an effective macroprudential complement to capital requirements. In particular, what shall be called dividend prudential targets: (i) are effective in smoothing the financial cycle by means of less volatile bank retained earnings, (ii) induce welfare gains associated to a Basel III-type of capital regulation, (iii) mainly operate through their cyclical component, ensuring that long-run dividend payouts remain unaffected, (iv) are associated to a sanctions regime which acts as an insurance scheme for the real economy and allows bankers to optimally deviate from the target. The latter is a property that may be crucial to tackle one of the main potential critiques dividend-based prudential rules may have to face. The negative impact dividend regulation could have on market volatility.

The simplicity of the model is instrumental to clearly identify the transmission mechanism through which the proposed policy rule operates. Yet, it comes at the cost of abstracting from a number of considerations that potentially constitute promising avenues for future research. Modeling one or more of the market imperfections that may be behind bank dividend policies should be helpful to match the data without having to rely on modeling devices such as equity payout adjustment costs.

Moreover, additional ingredients which are present in reality and that could possibly change some of the results have been omitted. On the one hand, assuming a positive probability of bank failure, as in Clerc et al. (2015), should reinforce the argument in favour of this complement to the existing macroprudential toolkit. On the other hand, incorporating outside equity in an environment in which bank owners can substitute their bank shares for alternative assets at a relatively low cost, may make the policy proposal less attractive. In addition, the literature has shown that the approach to modeling bank risk taking and systemic risk can notably influence macroprudential policy prescriptions (see, e.g., Martinez-Miera and Suarez 2014).

Lastly, optimal coordination between this type of prudential regulation and other macroeconomic policies should be considered as well (e.g., monetary policy). Based on the ECB annual report of 2016, one of the critiques the European Parliament (2017) has recently made to the ECB relates to this issue. "The European Parliament is concerned that euro area banks did not use the advantageous environment created by the ECB to strengthen their capital bases but rather, accord- 
ing to the Bank for International Settlements, to pay substantial dividends sometimes exceeding the level of retained earnings." 


\section{References}

[1] Acharya, V., Gujral, I., Kulkarni, N., and H. Shin, (2012). "Dividends and Bank Capital in the Financial Crisis of 2007-2009." Working paper, NYU-Stern and Princeton University.

[2] Acharya, V., Le, H. T., and H. Shin, (2017). "Bank Capital and Dividend Externalities." Review of Financial Studies, Society for Financial Studies, 30, 988-1018.

[3] Admati, A., DeMarzo, P., Hellwig, M., and P. Pfleiderer, (2013). "Fallacies, Irrelevant Facts, and Myths in the Discussion of Capital Regulation: Why Bank Equity is Not Expensive." Working Paper, Stanford GSB.

[4] Allen, F., and R. Michaely, (2003). "Payout policy." In Handbook of Economics of Finance, edited by G.M. Constantinides, M. Harris and R. Stulz, pp. 337-429. North-Holland. Amsterdam: Elsevier.

[5] Andrés, J., and O. Arce, (2012). "Banking Competition, Housing Prices and Macroeconomic Stability." Economic Journal, 122, 1346-1372.

[6] Andrés, J., Arce, O., and C. Thomas, (2013). "Banking competition, collateral constraints and optimal monetary policy." Journal of Money, Credit and Banking, 45, 87-125.

[7] Angelini, P., Neri, S., F. Panetta, (2014). "The Interaction between Capital Requirements and Monetary Policy." Journal of Money, Credit and Banking, 46, 1073-1112.

[8] Angeloni, I., and E. Faia, (2009). "A Tale of Two Policies: Prudential Regulation and Monetary Policy with Fragile Banks." Kiel Working Paper.

[9] Angeloni, I., and E. Faia, (2013). "Capital regulation and monetary policy with fragile banks." Journal of Monetary Economics, 60, 311-324.

[10] Bank for International Settlements (2014): 84th Annual Report, 2013/14.

[11] Begenau, J., (2016). "Capital Requirements, Risk Choice, and Liquidity Provision in a Business Cycle Model." Working Paper, Stanford GSB.

[12] Bernanke, B. S., Gertler, M. and S. Gilchrist, (1999). "The Financial Accelerator in a Quantitative Business Cycle Framework." in J. B. Taylor and M. Woodford, eds., Handbook of macroeconomics, Vol. 1C. Amsterdam: Elsevier Science, North-Holland, pp. 1341-1393.

[13] Clerc, L., Derviz, A., Mendicino, C., Moyen, S., Nikolov, K., Stracca, L., Suarez, J., and A. Vardoulakis, (2015). "Capital Regulation in a Macroeconomic Model with Three Layers of Default." International Journal of Central Banking, 11, 9-63. 
[14] Cohen, B. H., and M. Scatigna, (2016). "Banks and capital requirements: channels of adjustment." Journal of Banking and Finance, 29, S56-S69.

[15] Constâncio, V., (2017). Macroprudential policy in a changing financial system. Second ECB Macroprudential Policy and Research Conference, Frankfurt am Main, 11 May 2017.

[16] Christensen, I., and A. Dib, (2008). "The Financial Accelerator in an Estimated New Keynesian Model." Review of Economic Dynamics,11, 155-178.

[17] DeAngelo, H., DeAngelo, L., and Douglas J. Skinner, (2009). "Corporate Payout Policy." Foundations and Trends in Finance, now publishers, vol. 3(2-3), 95-287.

[18] Dewenter, K., L. and V. A. Warther, (1998). "Dividends, Asymmetric Information, and Agency Conflicts: Evidence from a Comparison of the Dividend Policies of Japanese and U.S. Firms." Journal of Finance, American Finance Association, 53, 879-904.

[19] European Parliament, Committee on Economic and Monetary Affairs (2017): Report on the European Central Bank Annual Report for 2016, November 2017.

[20] Galati, G. and R. Moessner, (2013). "Macroprudential policy-a literature review." Journal of Economic Surveys 27, 846-878

[21] Gerali, A., Neri, S., Sessa, L., and F. M. Signoretti, (2010). "Credit and Banking in a DSGE Model of the Euro Area."Journal of Money, Credit and Banking, 42, 107-141.

[22] Gertler, M., and P. Karadi, (2011). "A model of unconventional monetary policy." Journal of Monetary Economics, 58, 17-34.

[23] Gertler, M., and N. Kiyotaki, (2010). "Financial intermediation and credit policy in business cycle analysis." In: Friedman, B.M., Woodford, M. (Eds.), Handbook of Monetary Economics, vol. 3. Elsevier, pp. 547-599. Chapter 11.

[24] Goodhart, C. A., Peiris, E. U., Tsomocos, D., and A. Vardoulakis, (2010). "On Dividend Restrictions and the Collapse of the Interbank Market." Annals of Finance.

[25] Gropp,R., Mosk, T., Ongena, S. and C. Wix, (2018). "Banks Response to Higher Capital Requirements: Evidence from a Quasi-Natural Experiment." The Review of Financial Studies, 24 .

[26] Iacoviello, M., (2005). "House Prices, Borrowing Constraints, and Monetary Policy in the Business Cycle." American Economic Review, 95, 739-764. 
[27] Iacoviello, M., (2015). "Financial Business Cycles." Review of Economic Dynamics, 18, 140164.

[28] Jermann, U., and V. Quadrini, (2012). "Macroeconomic effects of financial shocks." The American Economic Review, 102, 238-271.

[29] Kim, J., Kim, S., Schaumburg, E., and C. Sims, (2008). "Calculating and using second order accurate solutions of discrete time dynamic equilibrium models." Journal of Economic Dynamics and Control, 32 , 3397-3414.

[30] Kiyotaki, N., and J. Moore, (1997). "Credit Cycles." Journal of Political Economy, 105, 211248.

[31] La Porta, R., Lopez-de-Silanes, F., Shleifer, A. and R. Vishny, (2000). "Agency Problems and Dividend Policies around the World." Journal of Finance, 55,1-33.

[32] Lintner, J., (1956). "Distribution of Incomes of Corporations Among Dividends, Retained Earnings, and Taxes." American Economic Review, 46, 97-113.

[33] Martinez-Miera, D., and J. Suarez, (2014). "Banks Endogenous Systemic Risk Taking." CEMFI, mimeo.

[34] Mendicino, C., Nikolov, K., Supera, D. and J. Suarez, (2018). "Optimal dynamic capital requirements." Journal of Money, Credit and Banking, 50, 1271-1297.

[35] Mendicino, C., and M. T.Punzi, (2014). "House prices, capital inflows and macroprudential policy." Journal of Banking \& Finance, Elsevier, 49, 337-355.

[36] Miller, M.H., and K. Rock, (1985). "Dividend Policy Under Asymmetric Information." Journal of Finance, 40, 1031- 51.

[37] Neumeyer, P.A., and F. Perri, (2005). "Business cycles in emerging economies: the role of interest rates." Journal of Monetary Economics 52, 345-380.

[38] Quint, D., and P. Rabanal, (2014). "Monetary and macroprudential policy in an estimated DSGE model of Euro Area." International Journal of Central Banking, 10, 169-236.

[39] Schmitt-Grohe, S. and M. Uribe, (2007). "Optimal Simple and Implementable Monetary and Fiscal Rules." Journal of Monetary Economics, 54, 1702-725.

[40] Shin, H.S., (2016). Bank capital and monetary policy transmission. The ECB and its Watchers XVII conference, Frankfurt, 7 April 2016. 

Table 1: Optimized rules and prudential losses; collateral shock (basic model)

\begin{tabular}{|c|c|c|c|c|c|c|c|}
\hline & & & $\sigma_{B}^{2}$ & $\sigma_{B / Y}^{2}$ & $\sigma_{K_{b}}^{2}$ & $\sigma_{Y}^{2}$ & $\sigma_{q}^{2}$ \\
\hline (i) Baseline & & Loss & 0.002002 & 0.00221 & 0.000020 & 0.000009 & 0.000639 \\
\hline \multirow[t]{4}{*}{ (ii) $\left\{\rho_{d}, \rho_{x}\right\}$} & & Loss & 0.000237 & 0.00023 & 0.000002 & 0.000008 & 0.000466 \\
\hline & Loss & Variation $^{(1)}$ & -88.16 & -89.59 & -90.00 & -11.11 & -27.07 \\
\hline & & $\rho_{d}^{(2)}$ & 0.535 & 0.535 & 0.529 & 0.556 & 0.000 \\
\hline & & $\rho_{x}$ & 100.33 & 100.43 & 99.60 & 78.25 & 12.36 \\
\hline \multirow[t]{3}{*}{ (iii) $\left\{\rho_{x}\right\}$} & & Loss & 0.000558 & 0.000556 & 0.000005 & 0.000008 & 0.000634 \\
\hline & Loss & s Variation & -72.13 & -74.84 & -75.00 & -11.11 & -0.78 \\
\hline & & $\rho_{x}$ & 54.80 & 54.80 & 54.80 & 54.80 & 6.44 \\
\hline
\end{tabular}

Note:(1) Percentage changes in the value of the loss function under the policy scenario associated to the optimized dividend prudential target, with respect to the baseline scenario. (2) Values of the autonomous component of the policy rule have been normalized by expressing them in terms of steady state bank profits. 
Table 2: Baseline parameter values

A) Pre-set params

\begin{tabular}{clll}
\hline Parameter & Description & Value & Source \\
\hline$\varphi$ & Inverse of the Frisch elasticity & 1 & Standard \\
$\sigma$ & Intertemporal elasticity of substitution & 1 & Standard \\
$\delta_{k}$ & Depreciation rate of physical capital & 0.025 & Standard \\
$\alpha$ & Capital share in production & 0.25 & Standard \\
$m_{H}$ & Loan-to-value ratio on housing & 0.7 & Standard \\
$m_{k}$ & Loan-to-value ratio on capital & 0.25 & Gerali et al. (2010) \\
$\phi_{i}$ & HH credit adj.cost param & 0.037 & Iacoviello (2015) \\
$\phi_{e}$ & NFC credit adj. cost param & 0.06 & Iacoviello (2015) \\
$\kappa$ & Dividend adj. cost parameter & 0.426 & Jermann \& Quadrini (2012) \\
$\psi_{k}$ & Capital adj. cost parameter & 0.5 & Mendicino et al. (2010) \\
\hline
\end{tabular}

B) Calibration

\begin{tabular}{clll}
\hline Parameter & Description & Value & Target ratio \\
\hline$\beta_{p}$ & Savers' discount factor & 0.9943 & $R_{h}^{s s}=(1.023)^{1 / 4}$ \\
$\beta_{i}$ & Borrowers' discount factor & 0.95 & $\left(r_{b}^{s s}-r_{d}^{s s}\right)=3.4$ \\
$j_{p}$ & Savers' housing weight & 0.087 & $x_{p}\left(q^{s s} H^{s s}\right) /\left(4 Y^{s s}\right)=1.575$ \\
$j_{i}$ & Borrowers' housing weight & 0.2 & $x_{i}\left(q^{s s} H^{s s}\right) /\left(4 Y^{s s}\right)=1.222$ \\
$\omega_{e}$ & Fraction of firms owned by $\mathrm{HH}_{p}$ & 1 & $B_{e}^{s s} / B^{s s}=0.4510$ \\
$\omega_{b}$ & Fraction of banks owned by $\mathrm{HH}_{p}$ & 0 & $B_{i}^{s s} / Y^{s s}=2.1403$ \\
$m_{H}$ & Wage bill paid in advance & 0 & $B_{e}^{s s} / Y^{s s}=1.7581$ \\
$\gamma_{e}$ & Debt-to-assets, NFC risk-adjusted & 0.8522 & $\gamma_{e} / \gamma_{i}=2.1176$ \\
$\gamma_{i}$ & Debt-to-assets, HH risk-adjusted & 0.9302 & $K_{b}^{s s} / B^{s s}=0.105$ \\
$\delta$ & Depreciation rate of bank capital & 0.038 & $d^{s s} / J_{b}^{s s}=0.563$ \\
\hline
\end{tabular}

Note: abreviations $\mathrm{HH}$ and NFC refer to households and non-financial corporations (entrepreneurs), respectively. HHp stands for patient households. 
Table 3: Steady state ratios

\begin{tabular}{|c|c|c|c|}
\hline Variable & Description & Model & Data \\
\hline$C^{s s} / Y^{s s}$ & Total consumption-to-GDP ratio & 0.7988 & 0.7607 \\
\hline$I^{s s} / Y^{s s}$ & Gross fixed capital formation-to-GDP ratio & 0.1853 & 0.2119 \\
\hline $4 \times r_{b}^{s s}$ & Annualized bank rate on loans (per cent) & 5.85 & 5.6 \\
\hline $4 \times r_{d}^{s s}$ & Annualized bank rate on deposits (per cent) & 2.293 & 2.3 \\
\hline$\left(r_{b}^{s s}-r_{d}^{s s}\right)$ & Annualized Bank Spread (per cent) & 3.565 & 3.4 \\
\hline$\left(1-\gamma_{e}\right) /\left(1-\gamma_{i}\right)$ & Capital requirement of NFC loans-to-mortgage loans & 2.1176 & 2.1176 \\
\hline$K_{b}^{s s} / B^{s s}$ & Capital requirements on mortgage and NFC loans & 0.1044 & 0.105 \\
\hline$B_{i}^{s s} /\left(Y^{s s}\right)$ & Hh loans-to-GDP ratio & 2.225 & 2.140 \\
\hline$B_{e}^{s s} /\left(Y^{s s}\right)$ & Hh loans-to-GDP ratio & 1.773 & 1.758 \\
\hline$B_{i}^{s s} / B^{s s}$ & Fraction of $\mathrm{HH}$ loans & 0.5565 & 0.5490 \\
\hline$B_{e}^{s s} / B^{s s}$ & Fraction of NFC loans & 0.4435 & 0.4510 \\
\hline$d_{b}^{s s} / J_{b}^{s s}$ & Bank dividend payout-ratio & 0.5797 & 0.563 \\
\hline$x_{i}$ & Fraction of indebted $\mathrm{HH}$ & 0.437 & 0.437 \\
\hline$x_{i}\left(q^{s s} H^{s s}\right) /\left(4 Y^{s s}\right)$ & Indebted $\mathrm{HH}$ wealth-to-GDP ratio & 0.8042 & 1.222 \\
\hline$x_{p}\left(q^{s s} H^{s s}\right) /\left(4 Y^{s s}\right)$ & Non-indebted HH wealth-to-GDP ratio & 1.6326 & 1.575 \\
\hline
\end{tabular}

Note: Data targets have been constructed from euro area quarterly data for the period 2002:I-2018:II. The exceptions are the following: annualized bank rates, which have been taken from constructed series presented in Gerali et al. (2010), and the target for capital requirements, which has been based on the Basel III regime. Data sources are Eurostat, ECB and Bloomberg. 
Table 4: Welfare Gains

\begin{tabular}{lcc}
\hline \hline \multicolumn{1}{c}{ Shocks } & Savers & Borrowers \\
All shocks & 0.1863 & 0.1863 \\
(i) No financial shocks & 0.3223 & -0.1278 \\
$*$ No HH collateral shock & 0.1759 & 0.1932 \\
$*$ No NFC collateral shock & 0.1873 & 0.1848 \\
*No equity shock & 0.3316 & -0.1333 \\
(ii) No preference shocks & -0.1562 & 0.3534 \\
$*$ No housing pref shock & -0.0955 & 0.3153 \\
$*$ No consumption pref shock & 0.1254 & 0.2244 \\
(iii) No technology shock & 0.2070 & 0.1473 \\
\hline \hline
\end{tabular}

Note: Second-order approximation to the welfare gains associated to the benchmark optimized dividend prudential target in which none or some of the shocks are shut down. welfare gains are expressed in percentage permanent consumption. 
Table 5: Welfare Gains and capital regulation

\begin{tabular}{|c|c|c|c|}
\hline$(1-\gamma)$ & $\rho_{x}$ & Savers & Borrowers \\
\hline \multicolumn{4}{|c|}{ Capital ratio increases } \\
\hline \multicolumn{4}{|c|}{ (i) 1.5 p.p. increase in $(1-\gamma)$} \\
\hline$* 0.12$ & 0 & -0.7021 & -0.0112 \\
\hline$* 0.12$ & 67.495 & -0.4153 & 0.2777 \\
\hline \multicolumn{4}{|c|}{ Alternative capital scenarios } \\
\hline \multicolumn{4}{|c|}{ (ii) Reoptimization wrt. $\rho_{x}$} \\
\hline$*_{0} 0.08$ & 59.84 & 0.1067 & 0.1067 \\
\hline$* 0.105$ & 67.495 & 0.18625 & 0.18625 \\
\hline$*_{0} 0.12$ & 85.00 & 0.2889 & 0.2889 \\
\hline \multicolumn{4}{|c|}{ (iii) No reoptimization wrt. $\rho_{x}$} \\
\hline$* 0.08$ & 67.495 & 0.1630 & 0.0925 \\
\hline$* 0.105$ & 67.495 & 0.18625 & 0.18625 \\
\hline$* 0.12$ & 67.495 & 0.1668 & 0.2733 \\
\hline
\end{tabular}

Note: Part (i) highlights the differences in welfare gains between increasing the capital ratio with and without the introduction of a dividend prudential target, with respect to the baseline scenario.Parts (ii) and (iii) summarize the welfare effects of dividend-based prudential rules under alternative capital scenarios. Hence, in this case, the baseline and the policy scenarios are associated to the same capital ratio. A capital ratio that may no longer coincide with its baseline calibration value. 
Table 6: Welfare Gains and the $\mathrm{CCyB}$

\begin{tabular}{lcccc}
\hline \hline & $\gamma_{x}$ & $\rho_{x}$ & Savers & Borrowers \\
(i) $\left\{\gamma_{x}\right\}$ & & & & \\
$* \arg \max _{\gamma_{x}} V_{0}^{p}$ & -0.453 & 67.495 & 2.1125 & 2.8712 \\
$* \arg \max _{\gamma_{x}} V_{0}^{i}$ & -0.567 & 67.495 & 2.0761 & 2.9110 \\
(ii) $\left\{\gamma_{x}, \rho_{x}\right\}$ & & & & \\
$* \arg \max _{\gamma_{x}, \rho_{x}} V_{0}^{p}$ & -0.478 & 80 & 2.7979 & 3.5501 \\
$* \arg \max _{\gamma_{x}, \rho_{x}} V_{0}^{i}$ & -0.588 & 80 & 2.7575 & 3.5905 \\
\hline \hline
\end{tabular}

Note: In these two cases, there is no optimized policy parameter value/s for which welfare gains are identical between patient and impatient households. Hence, the table reports the results of macroprudential policies that individually maximize savers and borrowers' welfare.

Table 7:Robustness Checks

$\rho_{x} \quad$ Welfare gains

(i) Policy indicator, $x_{t}$

$\begin{array}{llc}* \mathrm{~B} / \mathrm{Y} & 67.495 & 0.18625 \\ *_{\mathrm{B}} & 38.242 & 0.0757 \\ { }^{*} \mathrm{q} & 110.95 & 0.18973\end{array}$

(ii) Adj cost param, $\kappa$

\begin{tabular}{ccc}
$*_{0} 0.10$ & 321.48 & 0.2445 \\
${ }^{*} 0.426$ & 67.495 & 0.18625 \\
$* 1.00$ & 25.031 & 0.1227 \\
\hline \hline
\end{tabular}


(a) SX7E Dividend payout ratio (percent)

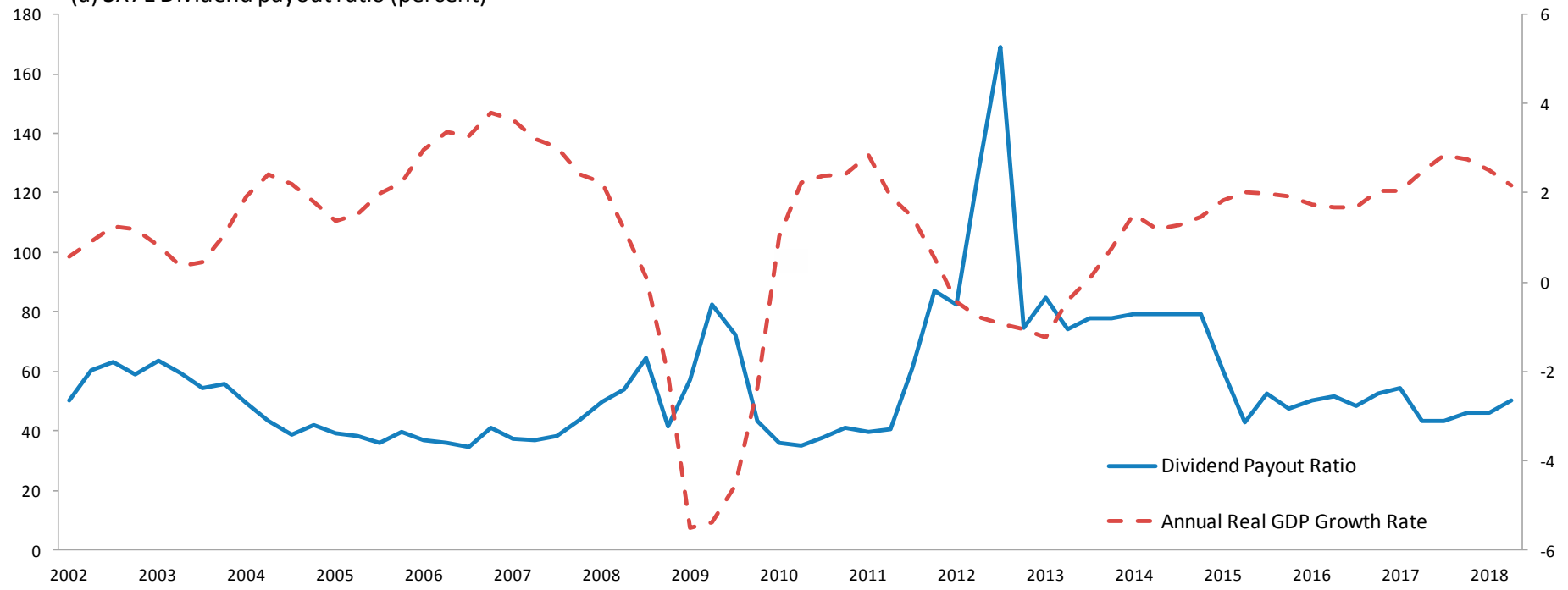

(b) SX7E Dividends and earnings (billion Euros)

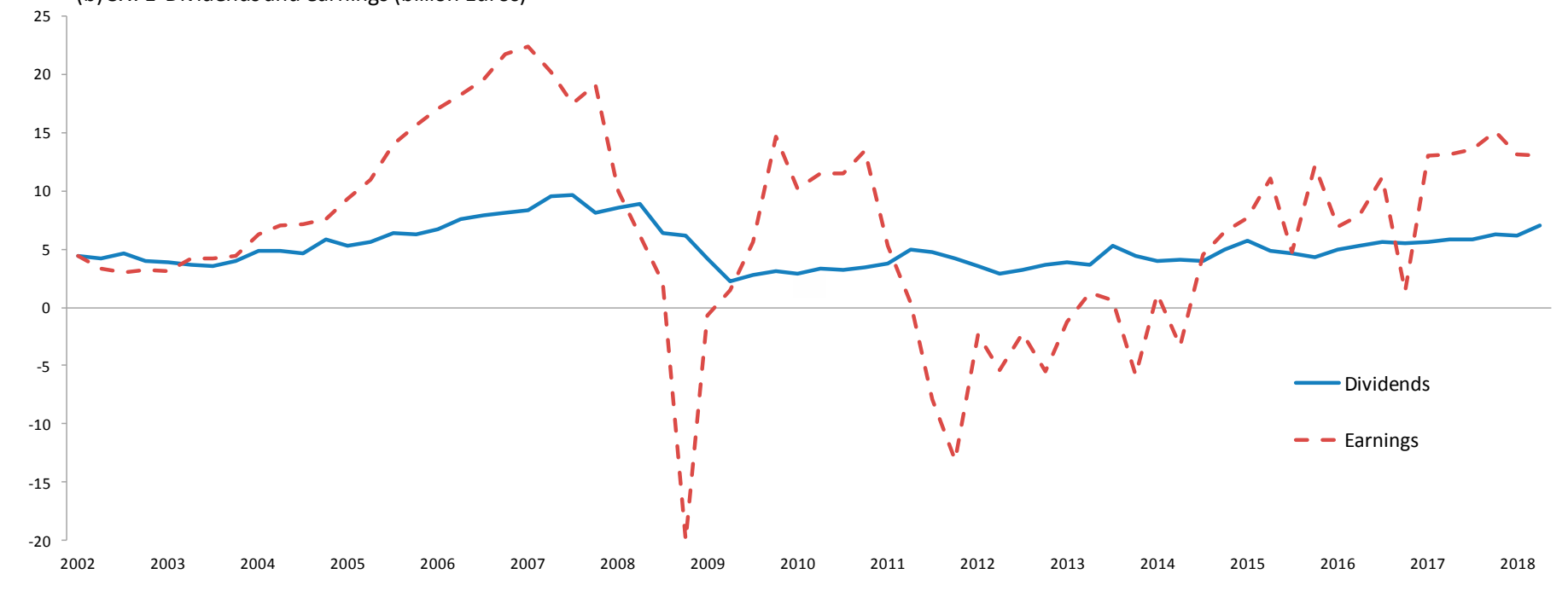

(c) SX7E Equity and retained earnings (million Euros)

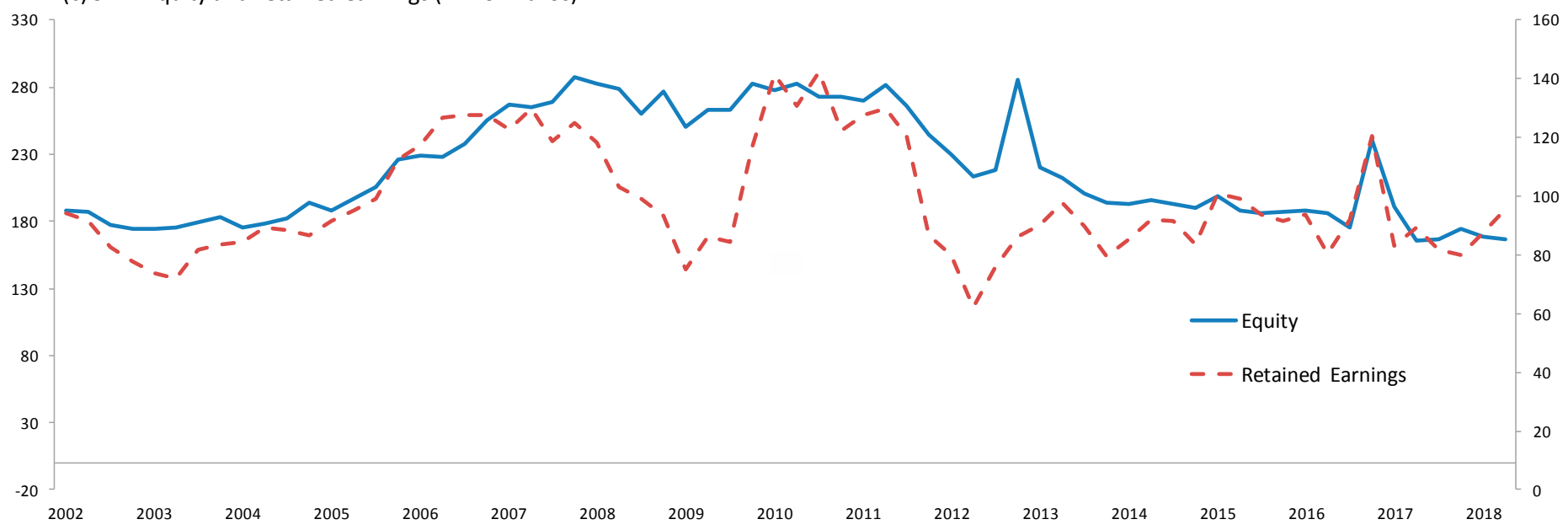

Figure 1: Bank dividends and earnings in the euro area. 2002:I - 2018:II

Note: (i) SX7E refers to the Euro Stoxx Banks Index. (ii) When applicable, the secondary y-axis corresponds to the dashed line. (iii) Data sources: Bloomberg, Eurostat, and own calculations. 
Figure 2: Impulse-responses to a negative collateral shock (basic model)
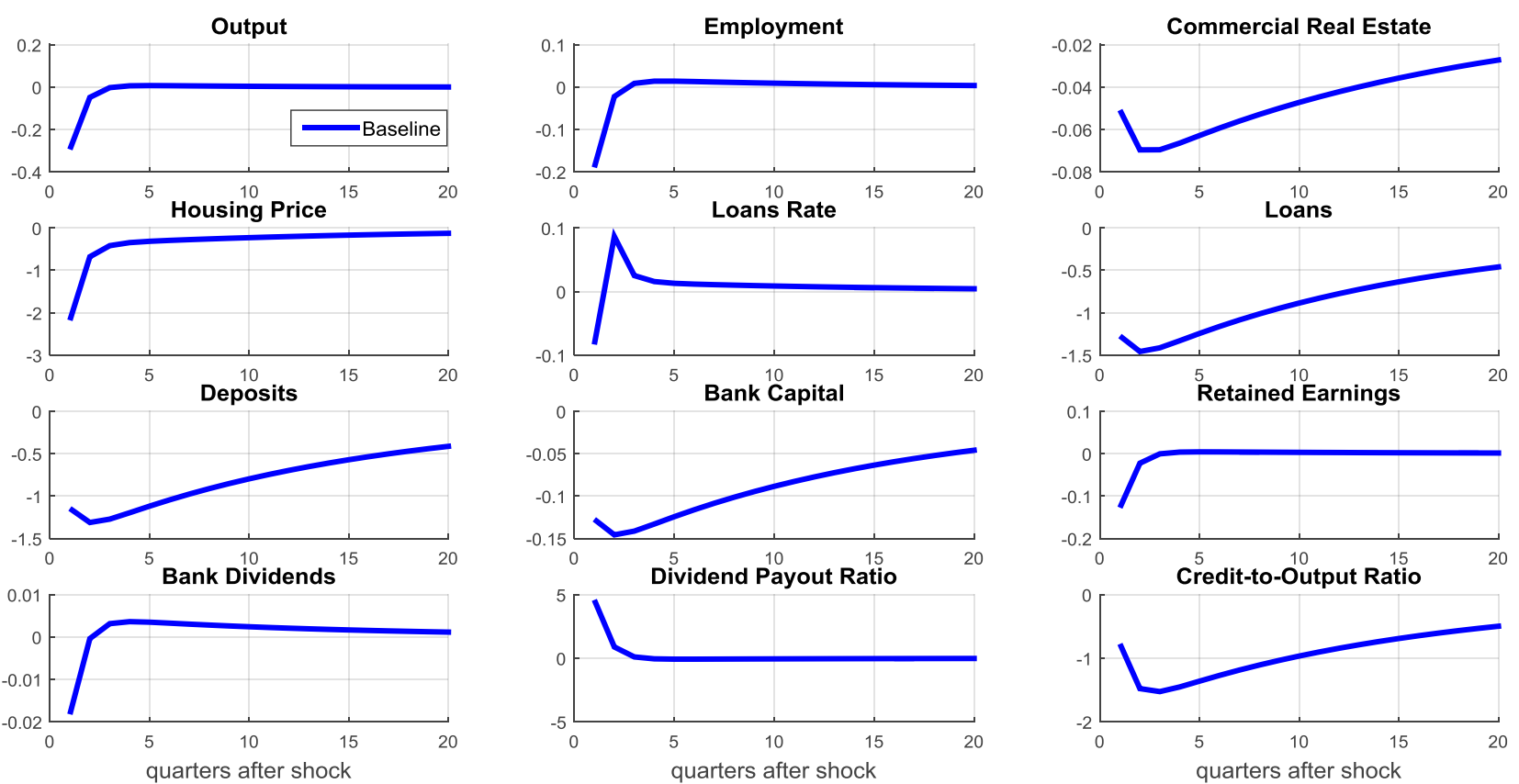

Figure 3: Impulse-responses to a negative collateral shock (basic model, optimized prudential rules)
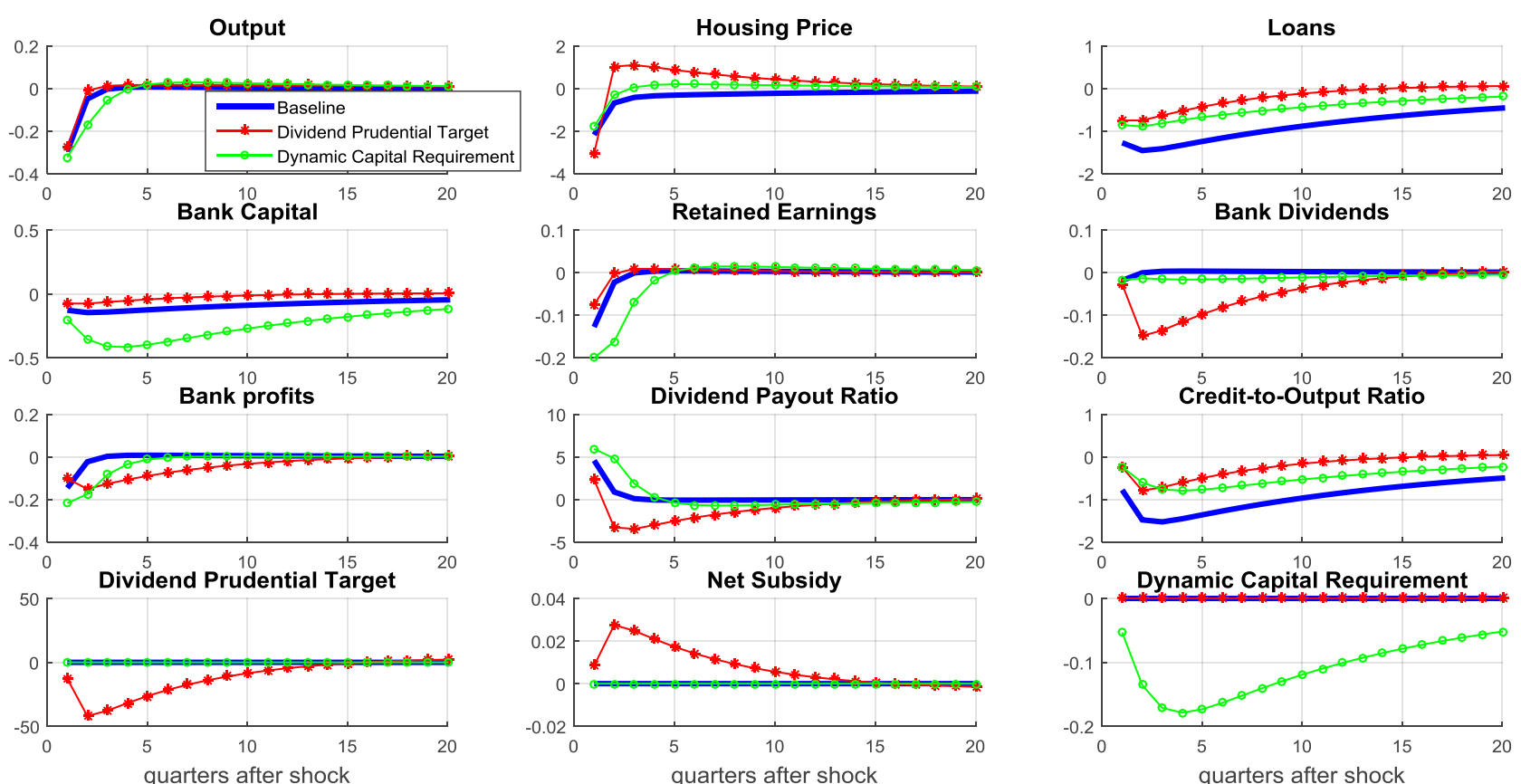
Figure 4: Welfare effects of ceteris paribus changes in $\rho_{\mathrm{d}}$ and $\rho_{\mathrm{x}}$
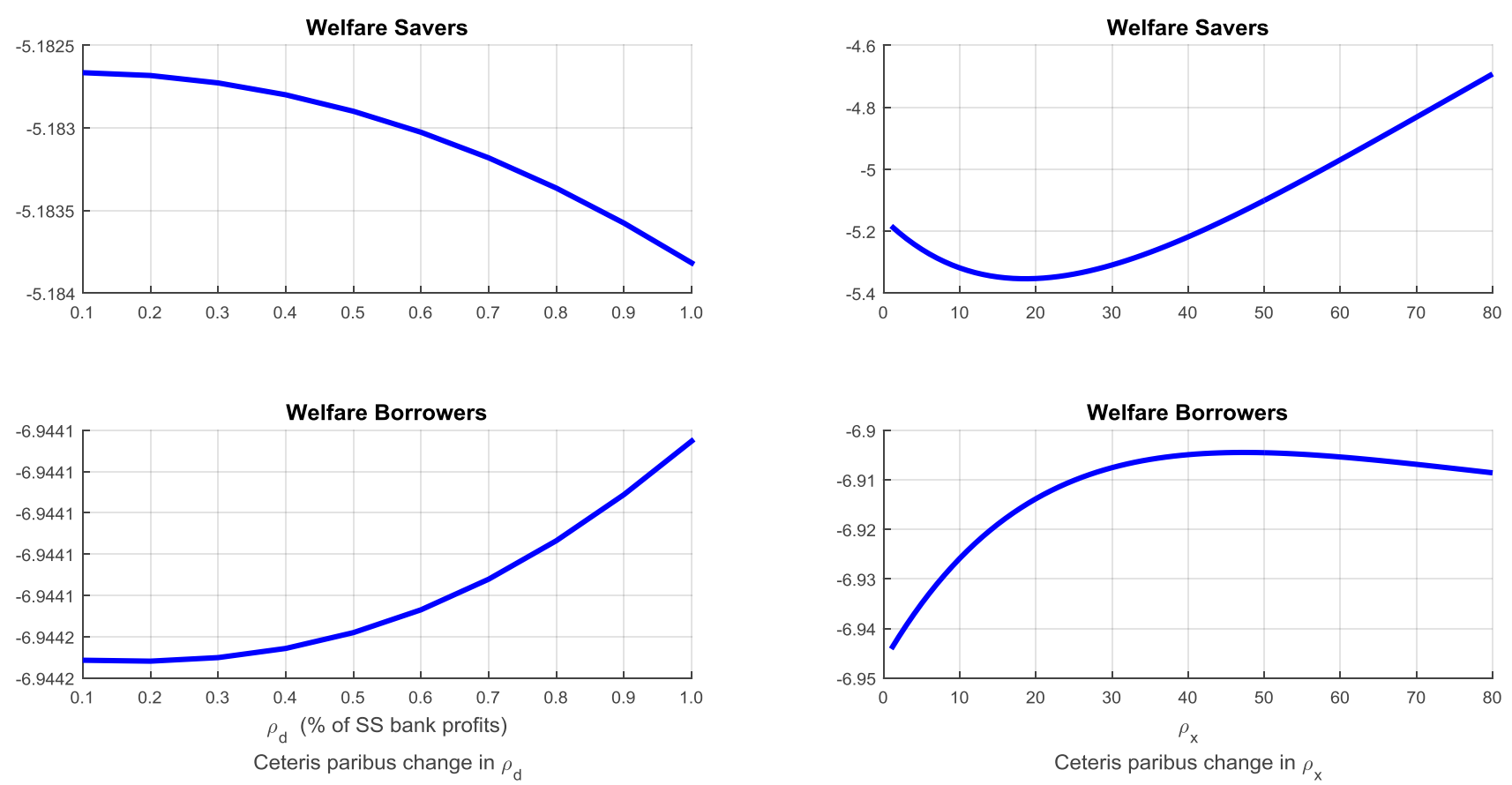

Figure 5: Welfare effects of ceteris paribus changes in $\rho_{\mathrm{x}}$ (shutting down shocks one by one)
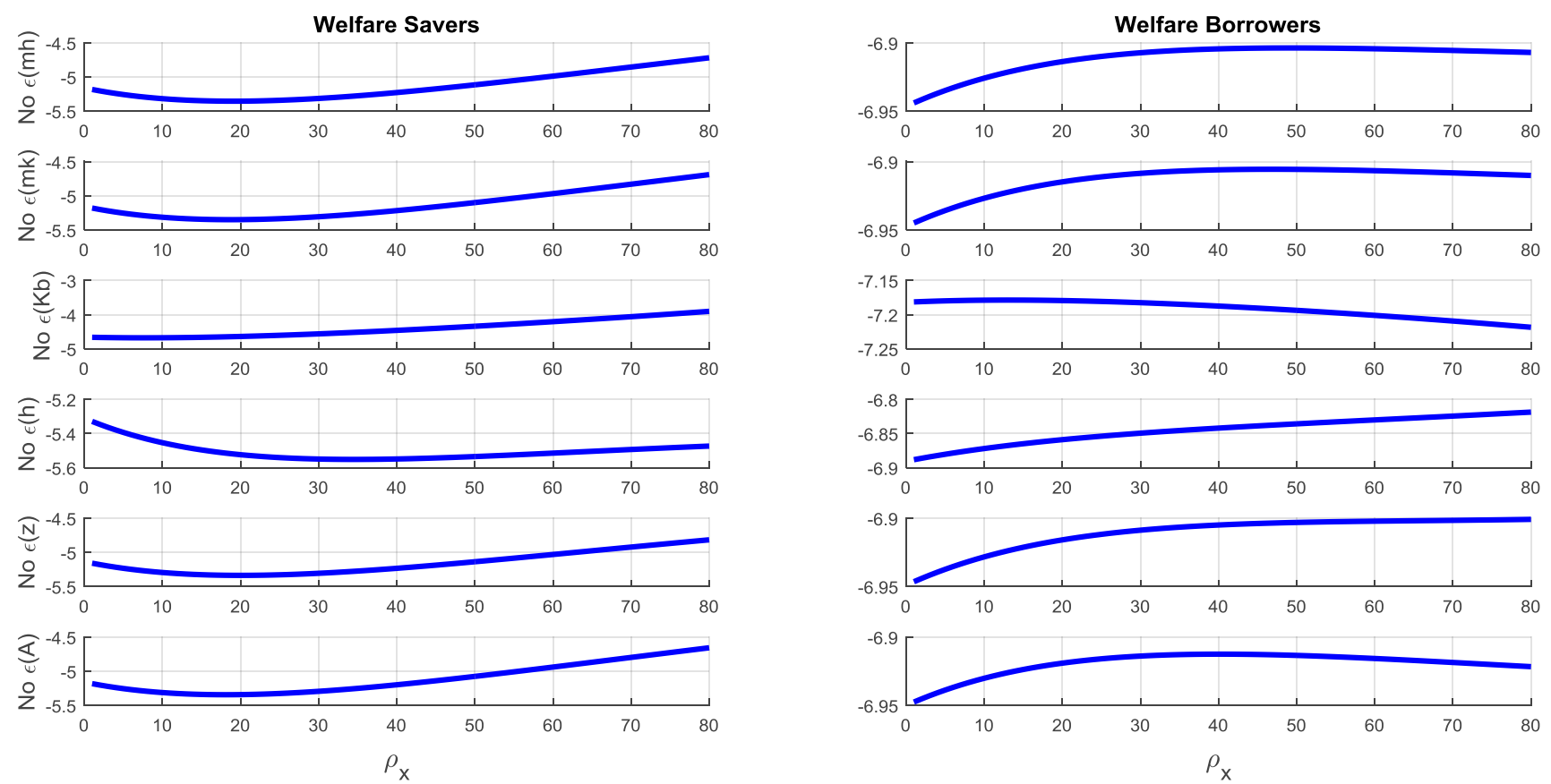
Figure 6: Welfare effects of ceteris paribus changes in $\gamma_{\mathrm{x}}$ and $\rho_{\mathrm{x}}+\gamma_{\mathrm{x}}$
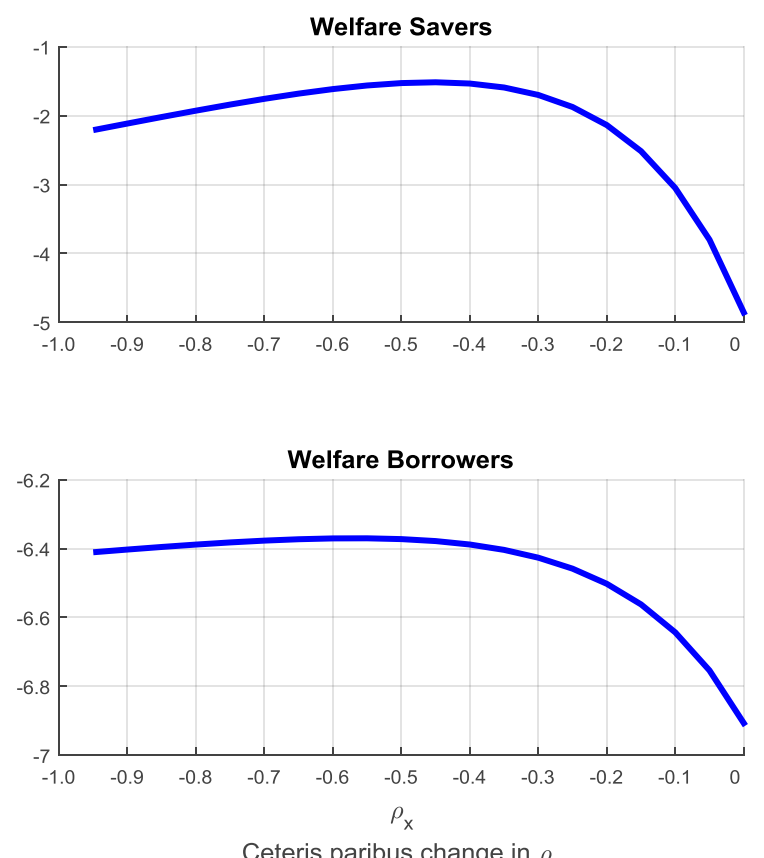

Ceteris paribus change in $\rho_{\mathrm{x}}$

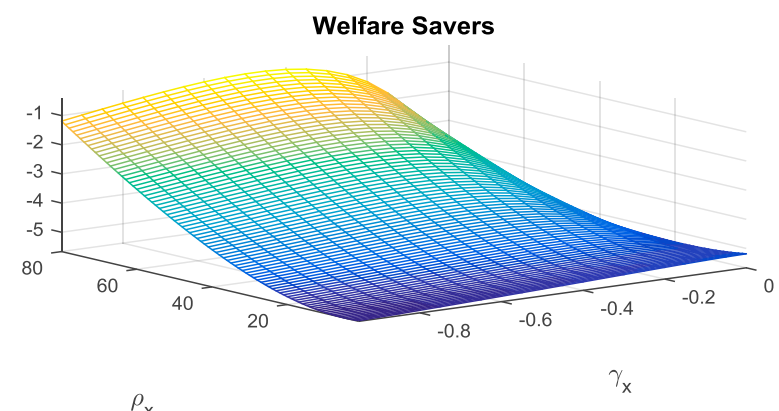

Welfare Borrowers

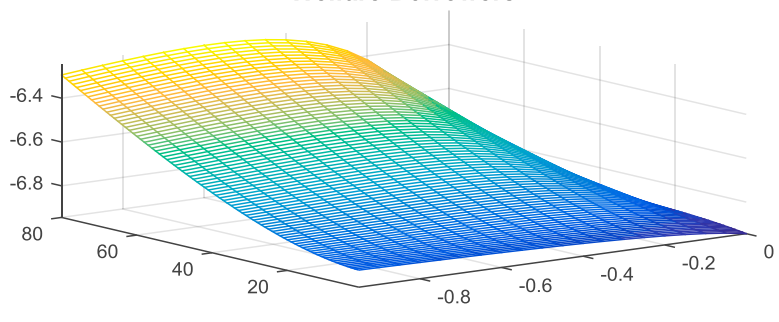

$\rho_{\mathrm{X}}$

Figure 7: Impulse-responses to a negative collateral shock (extended model, macroprudential policy scenarios)
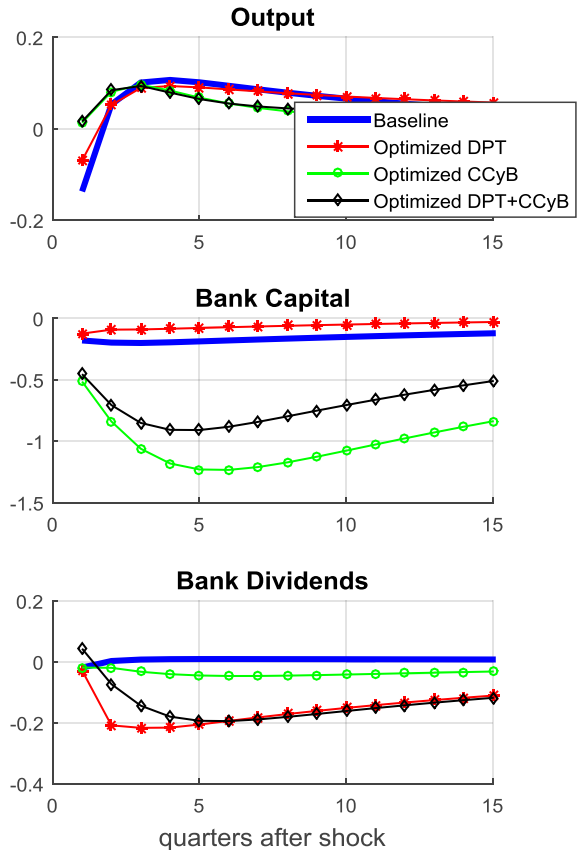
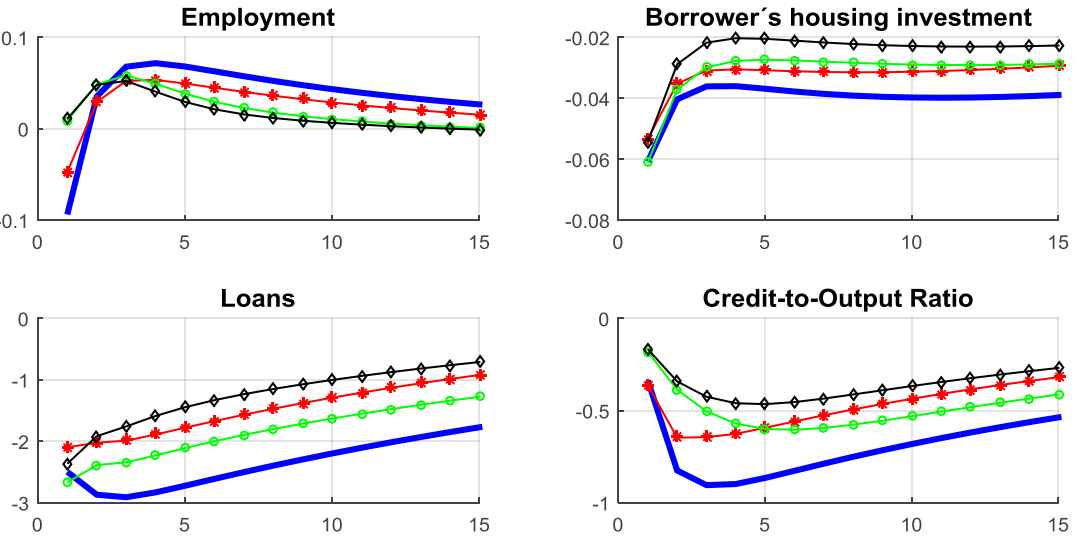

Credit-to-Output Ratio
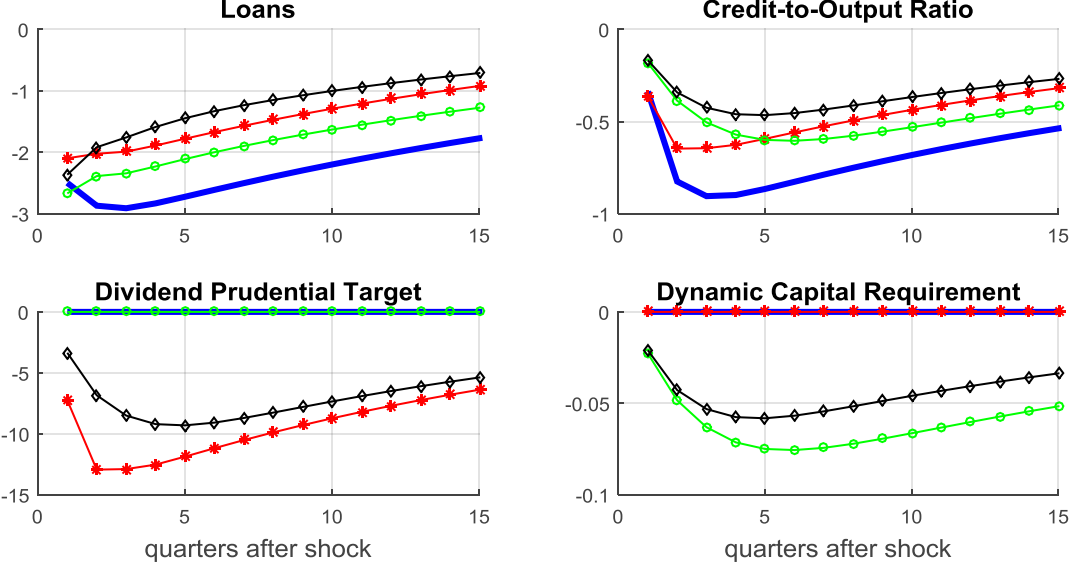
Figure 8: Robustness checks: $\kappa$ (welfare effects of ceteris paribus changes in $\rho_{\mathrm{x}}$ )
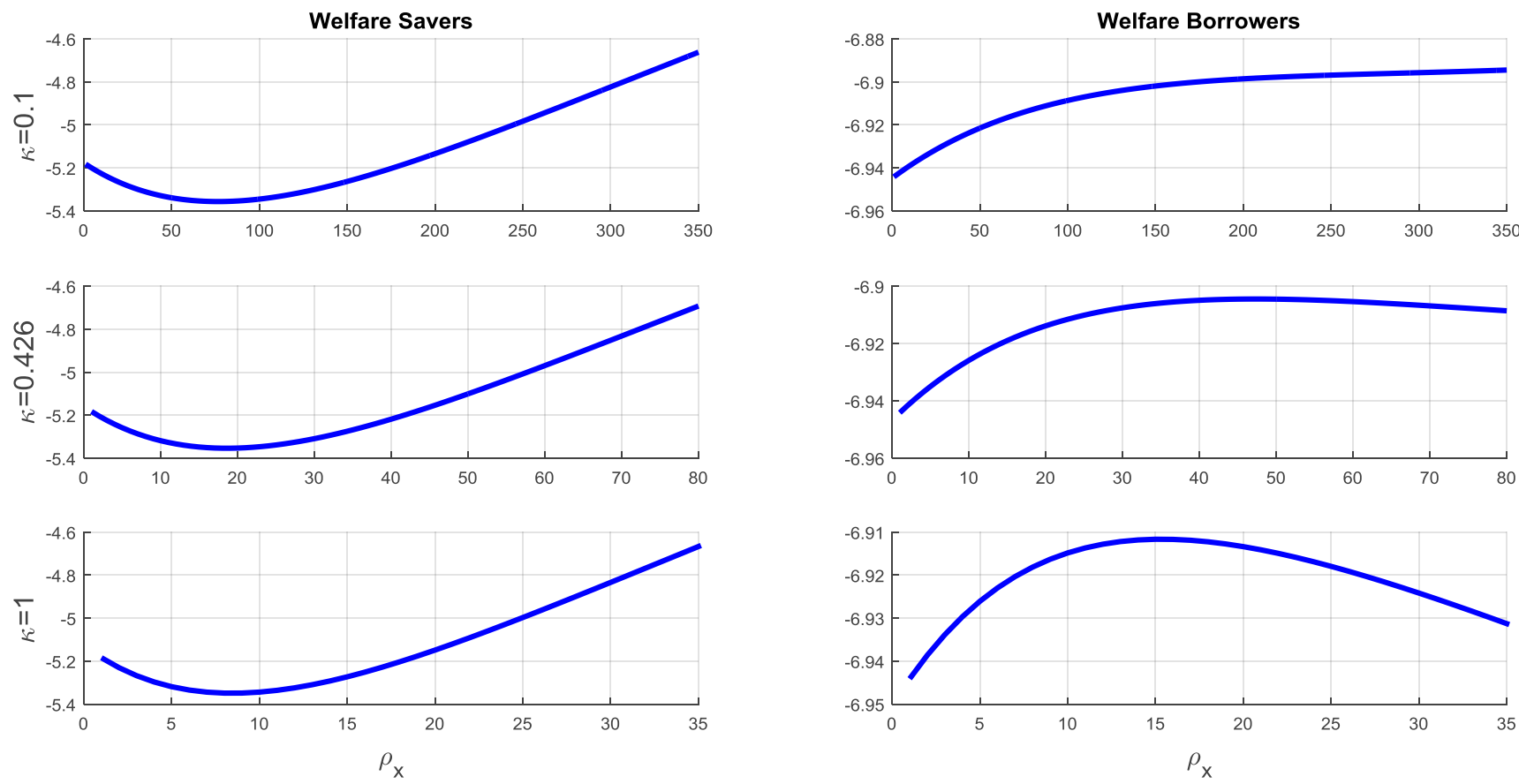

Figure 9: Robustness checks: $\mathrm{x}$ (welfare effects of ceteris paribus changes in $\rho_{\mathrm{x}}$ )
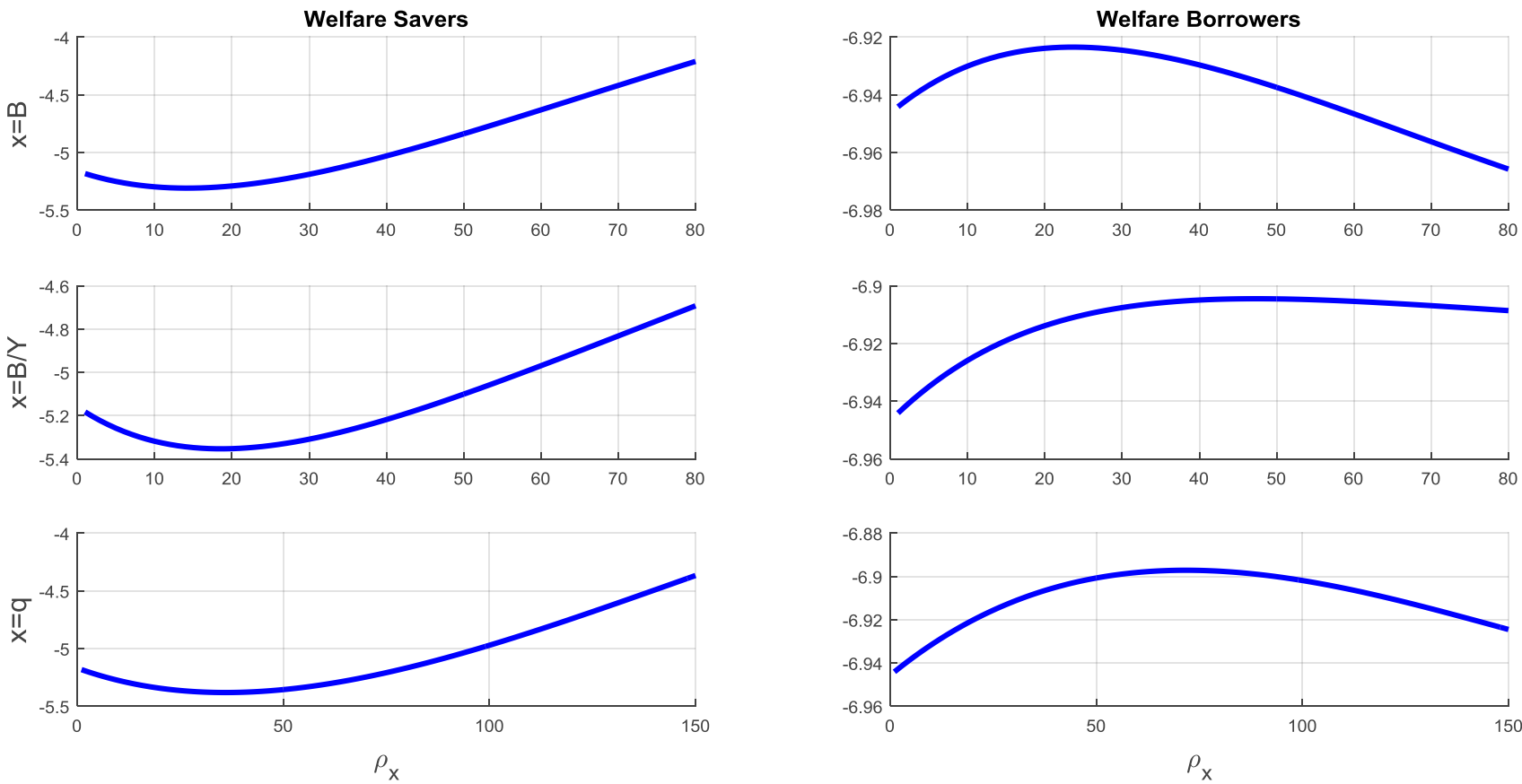



\section{A Data and Sources}

Gross domestic product: Gross domestic product at market prices, Chain-linked volumes (rebased), Domestic currency (may include amounts converted to the current currency at a fixed rate), Seasonally and working day-adjusted. Source: Eurostat.

Final Consumption: Final consumption expenditure at market prices, Chain linked volumes (2010), Seasonally and calendar adjusted data. Source: Eurostat.

Gross fixed capital formation: Gross fixed capital formation at market prices, Chain linked volumes (2010), Seasonally and calendar adjusted data. Source. Source: Eurostat.

Households Housing Wealth: Housing wealth (net) of Households and non profit institutions serving households sector (NPISH), Current prices, Euros. ESA 2010. Source: European Central Bank.

Business Loans: Outstanding amounts at the end of the period (stocks) of loans from MFIs excluding ESCB reporting sector to Non-Financial corporations (S.11) sector, denominated in Euros. Source: MFI Balance Sheet Items Statistics (BSI Statistics), Monetary and Financial Statistics (S/MFS), European Central Bank.

Households Loans: Outstanding amounts at the end of the period (stocks) of loans from MFIs excluding ESCB reporting sector to Households and non-profit institutions serving households (S.14 \& S.15) sector, denominated in Euros. Source: MFI Balance Sheet Items Statistics (BSI Statistics), Monetary and Financial Statistics (S/MFS), European Central Bank.

Dividend Payout Ratio: Fraction of net income payed to shareholders in dividends, in percentage. Calculated as: Total Common Dividends*100 / Income Before Extraordinary Items Less Minority and Preferred Dividends. Capitalization-weighted sum of the SX7E members. Source: Bloomberg.

Dividends: Dividends paid to common shareholders from the profits of the company. Includes regular cash as well as special cash dividends for all classes of common shareholders. Excludes return of capital and in-specie dividends. For the cases in which dividends attributable to the period are not disclosed, dividends are estimated by multiplying the Dividend per Share by the number of Shares Outstanding. Simple sum of the SX7E members. Seasonally adjusted data (TRAMO/SEATS). Source: Bloomberg.

Earnings: Net Income Available To Common Shareholders. Calculated as: Net Income - Total Cash Preferred Dividend - Other Adjustments. Simple sum of the SX7E members. Seasonally adjusted data (TRAMO/SEATS). Source: Bloomberg.

Retained Earnings: Cumulative undistributed earnings. Includes net unrealized gain (loss) on securities held for sale and other items included in accumulated comprehensive income (net of tax). Includes deferred compensation to officers. Retained earnings are decreased by the amount 
of treasury stock. Reserves resulting from revaluation of assets in many countries are included as a part of shareholders' equity and are included. Capitalization-weighted sum of the SX7E members. Seasonally adjusted data (TRAMO/SEATS). Source: Bloomberg.

Total Equity: Firm's total assets minus its total liabilities. Calculated as: Common Equity + Minority Interest + Preferred Equity. Capitalization-weighted sum of the SX7E members. Source: Bloomberg. 


\section{B Equations of the Extended Model}

This section presents the full set of equilibrium equations of the extended model.

\section{B.1 Patient Households}

Patient households seek to maximize (20) subject to the following buget constraint

$$
C_{p, t}+D_{t}+q_{t}\left(H_{p, t}-H_{p, t-1}\right)=\left(R_{d, t-1}\right) D_{t-1}+W_{t} N_{p, t}+\omega_{b}\left(d_{b, t}+T_{t}\right)+\omega_{e} d_{e, t}
$$

Their choice variables are $C_{p, t}, D_{t}, H_{p, t}$ and $N_{p, t}$. The optimality conditions of the problem read

$$
\begin{gathered}
\frac{\varepsilon_{t}^{z}}{C_{p, t}}=\beta_{p} R_{d, t} E_{t}\left(\frac{\varepsilon_{t+1}^{z}}{C_{p, t+1}}\right) \\
\frac{q_{t} \varepsilon_{t}^{z}}{C_{p, t}}=\frac{j \varepsilon_{t}^{h}}{H_{p, t}}+\beta_{p} E_{t}\left(\frac{q_{t+1} \varepsilon_{t}^{z}}{C_{p, t+1}}\right) \\
\frac{W_{t} \varepsilon_{t}^{z}}{C_{p, t}}=N_{p, t}^{\phi}
\end{gathered}
$$

\section{B.2 Impatient Households}

The representative impatient household chooses the trajectories of consumption $C_{i, t}$, housing $H_{i, t}$, demand for labor $N_{i, t}$ and bank loans $B_{i, t}$ that maximize (20) subject to a budget constraint and a borrowing limit

$$
\begin{gathered}
C_{i, t}+R_{i, t-1} B_{i, t-1}+q_{t}\left(H_{i, t}-H_{i, t-1}\right)+\Phi_{i}\left(B_{i, t}\right)=B_{i, t}+W_{t} N_{i, t}+\left(1-\omega_{b}\right)\left(d_{b, t}+T_{t}\right)+\left(1-\omega_{e}\right) d_{e, t} \\
B_{i, t} \leq m_{i, t}^{H} E_{t}\left[\frac{q_{t+1}}{R_{i, t}} H_{i, t}\right]
\end{gathered}
$$

The resulting optimality conditions are

$$
\frac{W_{t} \varepsilon_{t}^{z}}{C_{i, t}}=N_{i, t}^{\phi}
$$




$$
\frac{\varepsilon_{t}^{z}}{C_{i, t}}\left[q_{t}-\left(1-\frac{\partial \Phi_{i}\left(B_{i, t}\right)}{\partial B_{i, t}}\right) E_{t}\left(m_{i, t}^{H} \frac{q_{t+1}}{R_{i, t}}\right)\right]=\frac{j \varepsilon_{t}^{h}}{H_{i, t}}+\beta_{i} E_{t}\left[\frac{q_{t+1} \varepsilon_{t+1}^{z}}{C_{i, t+1}}\left(1-m_{i, t}^{H}\right)\right]
$$

\section{B.3 Entrepreneurs}

Entrepreneurs seek to maximize (24) subject to a budget constraint, the available technology and the corresponding borrowing limit

$$
\begin{gathered}
d_{e, t}+R_{b, t} B_{e, t-1}+q_{t}^{k}\left[K_{e, t}-\left(1-\delta^{k}\right) K_{e, t-1}\right]+W_{t} N_{t}+\Phi_{e}\left(B_{e, t}\right)=Y_{t}+B_{e, t} \\
Y_{t}=A_{t} K_{e, t-1}^{\alpha} N_{t}^{1-\alpha} \\
B_{e, t} \leq m_{e, t}^{K} E_{t}\left(\frac{q_{t+1}^{k}}{R_{e, t+1}} K_{e, t}\right)-m^{N} W_{t} N_{t}
\end{gathered}
$$

Their choice variables are $d_{e, t}, K_{e, t}, B_{e, t}$ and $N_{t}$. The following optimality conditions can be derived from the first order conditions of the problem

$$
\begin{aligned}
& \frac{1}{d_{e, t}}\left[q_{t}^{k}-\left(1-\frac{\partial \Phi_{e}\left(B_{e, t}\right)}{\partial B_{e, t}}\right) m_{e . t}^{K} E_{t}\left(\frac{q_{t+1}^{k}}{R_{e, t+1}}\right)\right] \\
& =\Lambda_{0, t}^{e} E_{t}\left\{\frac{1}{d_{e, t+1}}\left[q_{t}^{k}\left(1-\delta^{k}\right)-q_{t+1}^{k} m_{e, t}^{K}\left(1-\delta^{k}\right)+\alpha\left(\frac{Y_{t+1}}{K_{e, t}}\right)\right]\right\} \\
& \frac{1}{d_{e, t}}\left[W_{t}+m^{N} W_{t}\left(1-\frac{\partial \Phi_{e}\left(B_{t}\right)}{\partial B_{t}}\right)-(1-\alpha) \frac{Y_{t}}{N_{t}}\right]=\Lambda_{0, t}^{e} E_{t}\left[\frac{1}{d_{e, t+1}} m^{N} W_{t} R_{e, t+1}\right]
\end{aligned}
$$

\section{B.4 Bankers}

The representative banker chooses the trajectories of dividend payouts $d_{b, t}$, loans to households $B_{i, t}$, loans to entrepreneurs $B_{e, t}$, and deposits $D_{t}$ that maximize (28) subject to a cash flow restriction and a borrowing limit (capital adequacy constraint) 


$$
\begin{gathered}
d_{b, t}+B_{i t}+B_{e, t}-D_{t}-(1-\delta)\left(B_{i, t-1}+B_{e, t-1}-D_{t-1}\right) \varepsilon_{t}^{k b} \\
=r_{e, t} B_{e, t-1}+r_{i, t-1} B_{i, t-1}-r_{d, t-1} D_{t-1}-\Phi_{b e}\left(B_{e, t}\right)-\Phi_{b i}\left(B_{i, t}\right)-\varphi\left(d_{b, t}\right) \\
D_{t}=\gamma_{i, t} B_{i, t}+\gamma_{e . t} B_{e, t}
\end{gathered}
$$

In order to incorporate the information of the balance sheet constraint in the optimization problem, there has been rearranged in equation (29) to substitute $K_{b, t}$ in expression (30). The law of motion for bank equity reads

$$
K_{b, t}=J_{b, t}-d_{b, t}+(1-\delta) K_{b, t-1} \varepsilon_{t}^{k b}
$$

The resulting optimality conditions read

$$
\begin{gathered}
\frac{\left(1-\gamma_{i, t}\right)+\frac{\partial \Phi_{b i}\left(B_{i, t}\right)}{\partial B_{i, t}}}{d_{b, t}^{\sigma}\left[1+\kappa\left(d_{b, t}-d_{t}^{*}\right)\right]}=\Lambda_{0, t}^{b} E_{t}\left\{\frac{\left(r_{i, t}-\gamma_{i, t} r_{d, t}\right)+\left(1-\gamma_{i, t}\right)(1-\delta) \varepsilon_{t}^{k b}}{d_{b, t+1}^{\sigma}\left[1+\kappa\left(d_{b, t+1}-d^{*}\right)\right]}\right\} \\
\frac{\left(1-\gamma_{e, t}\right)+\frac{\partial \Phi_{b e}\left(B_{e, t}\right)}{\partial B_{e, t}}}{d_{b, t}^{\sigma}\left[1+\kappa\left(d_{b, t}-d_{t}^{*}\right)\right]}=\Lambda_{0, t}^{b} E_{t}\left\{\frac{\left(r_{e, t+1}-\gamma_{e, t} r_{d, t}\right)+\left(1-\gamma_{e, t}\right)(1-\delta) \varepsilon_{t}^{k b}}{d_{b, t+1}^{\sigma}\left[1+\kappa\left(d_{b, t+1}-d^{*}\right)\right]}\right\}
\end{gathered}
$$

\section{B.5 Capital Goods Producers}

Capital-good-producing firms seek to maximize (32) with respect to net investment in physical capital, $I_{t}$. The resulting optimal condition is

$$
q_{k, t}=1+\frac{\psi_{k}}{\delta_{k}}\left(\frac{I_{t}}{K_{e, t-1}}-\delta_{k}\right)
$$

As standard in the literature, the law of motion for physical capital reads

$$
K_{e, t}=I_{t}+\left(1-\delta_{k}\right) K_{e, t-1}
$$




\section{B.6 Macroprudential Authority}

As in the basic model, the dividend prudetial target is specified as follows

$$
d_{t}^{*}=\rho_{d}+\rho_{\chi}\left(\frac{x_{t}}{x^{s s}}-1\right)
$$

Bank dividend deviations from such target are penalized with a proportional payment that takes the form of a sanction. Such penalty payments are transfered within the same period to bank owners. The corresponding net subsidy reads

$$
T_{t}=\frac{\kappa}{2}\left[\left(d_{b, t}^{a}-d_{t}^{*}\right)^{2}-\left(d_{b, t}-d_{b}^{s s}\right)^{2}\right]
$$

The prudential authority has full control over the banker's regulatory capital ratio $\left(1-\gamma_{t}\right)$ through the leverage ratio imposed by the borrowing limit (31)

$$
\gamma_{t}=\gamma+\gamma_{x}\left(\frac{x_{t}}{x^{s s}}-1\right)
$$

where $\gamma=\gamma_{i} \frac{B_{i}}{B}+\gamma_{e} \frac{B_{e}}{B}$

\section{B.7 Aggregation and market clearing}

Market clearing is implied by the Walras's law, by aggregating all the budget constraints. The aggregate resource constraint of the economy represents the equilibrium condition for the final goods market.

$$
Y_{t}=C_{p, t}+C_{i, t}+q_{t}^{k} I_{t}+K_{b, t}-(1-\delta) K_{b, t-1} \varepsilon_{t}^{k b}+A d j_{t}
$$

where the term $A d j_{t}$ corresdonds to the sum of all resources dedicated in the economy to adjust loans, bank dividends, and physical capital in period $t$.

In equilibrium, the housing market clears. The endowment of housing supply is fixed and normalized to unity

$$
\bar{H}=H_{p, t}+H_{i, t}
$$




\section{B.8 Shocks}

The following zero-mean, $\operatorname{AR}(1)$ shocks are present in the extended model: $\varepsilon_{t}^{z}, \varepsilon_{t}^{h}, \varepsilon_{t}^{m h}, \varepsilon_{t}^{m k}, A_{t}$, $\varepsilon_{t}^{k b}$. These shocks follow the processes given by:

$$
\begin{gathered}
\log \varepsilon_{t}^{z}=\rho_{z} \log \varepsilon_{t-1}^{z}+e_{z, t}, e_{z, t} \sim N\left(0, \sigma_{z}\right) \\
\log \varepsilon_{t}^{h}=\rho_{h} \log \varepsilon_{t-1}^{h}+e_{h, t}, e_{h, t} \sim N\left(0, \sigma_{h}\right) \\
\log \varepsilon_{t}^{m h}=\rho_{m h} \log \varepsilon_{t-1}^{m h}+e_{m h, t}, e_{m h, t} \sim N\left(0, \sigma_{m h}\right) \\
\log \varepsilon_{t}^{m k}=\rho_{m k} \log \varepsilon_{t-1}^{m k}+e_{m k, t}, e_{m k, t} \sim N\left(0, \sigma_{m k}\right) \\
\log A_{t}=\rho_{A} \log A_{t-1}+e_{A, t}, e_{A, t} \sim N\left(0, \sigma_{A}\right) \\
\log \varepsilon_{t}^{k b}=\rho_{m k} \log \varepsilon_{t-1}^{k b}+e_{k b, t}, e_{k b, t} \sim N\left(0, \sigma_{m k}\right)
\end{gathered}
$$




